Research Article

\title{
Research on IFC- and FDS-Based Information Sharing for Building Fire Safety Analysis
}

\author{
Jianyong Shi $\mathbb{D}$, Jicao Dao, Liu Jiang, and Zeyu Pan \\ Department of Civil Engineering, School of Naval Architecture, Ocean and Civil Engineering, Shanghai Jiao Tong University, \\ Shanghai 200240, China
}

Correspondence should be addressed to Jianyong Shi; shijy@sjtu.edu.cn

Received 30 July 2019; Revised 30 September 2019; Accepted 25 October 2019; Published 29 November 2019

Guest Editor: Endong Wang

Copyright (C) 2019 Jianyong Shi et al. This is an open access article distributed under the Creative Commons Attribution License, which permits unrestricted use, distribution, and reproduction in any medium, provided the original work is properly cited.

With the development of computer processors, vast numerical simulation tools are widely used by fire engineers to determine the spread of fire and smoke. However, the fire modeling practices are often highly time-consuming and cost-intensive especially for building geometry information which does limit the further implementation of building fire safety analysis. Although nowadays building information modeling (BIM) has become a buzzword in the Architecture, Engineering, and Construction (AEC) field to facilitate information integration and interoperability, data sharing and exchange are still weak in the traditional interoperability between BIM applications and fire simulation software, since the data schema of them are totally different. In this paper, a quick and accurate approach for information sharing for building fire safety analysis between mainstream BIM applications and widely used fire simulation software has been successfully implemented, based on Industry Foundation Classes (IFC) and Fire Dynamics Simulator (FDS). And, both geometrical building information and sematic information can be shared by this approach through the transformation of coordinate systems, outer database, and IFC file extension. The BIM model restoring fire simulation results can support other performance-based design of building, such as structural fire-resistant design and evacuation design. And, all of the analysis results including building fire simulation, structure safety design, and evacuation simulation can be integrated in Autodesk Revit, establishing a framework of IFC- and FDS-based information sharing for building fire safety analysis successfully. A gymnasium has been taken as a case study to illustrate the capability of this framework.

\section{Introduction}

With the rapid development of urbanization, fire simulation study has great significance in safety design of large-scale public buildings. The information of fire simulation results can also support optimization of architectural design, structural safety analysis, and evacuation simulation. The first step of fire simulation is to obtain the geometry information to establish the building model. However, the current fire simulation modeling method requires remodeling instead of utilizing the existing building model because of differences in data format and interfaces. Consequently, it probably leads that the data exchange and information sharing in fire modeling practice are in a great difficulty. The data and information provided and resulted by fire simulation software can only support single disciplines or tasks for field-related experts or professionals (i.e., fire safety or structural analysis), rather than an integrated analysis environment.

Meanwhile, BIM (Building Information Modeling) attracts widespread attention and has become a buzzword in the Architecture, Engineering, and Construction (AEC) field, which is defined as a digital model containing all information created or gathered throughout building life cycle and a technology to achieve the information integration and interoperability, which is different from traditional drawingbased or CAD technologies-based design and construction methods [1]. In addition, comprehensive and standardized data format and integrated process of BIM technology play a significant role in the effective utilization of building information [2]. And, it can coordinate contradiction better, which results in smoothing communication in each aspect of such projects and orderly cooperation between the systems. 
Thus, the Industry Foundation Classes (IFC) is developed as an open data model standard to serve the BIM interoperability needs of the industry $[3,4]$. IFC supports multiple different geometric representations and contains rich semantic information. It is most widely used in BIM and has already become a formally registered international standard and as an international standard for 3D data exchange between different BIM software tools for many years.

However, the current fire simulation software and mainstream BIM applications are still locked into "information islands" which means it is inefficient for building model transmission, conversion, and model information storage, so that it does hinder the development of BIM technology in the research field of fire safety.

The main limitations of current data sharing between BIM applications and fire simulation software are mainly addressed in the difference of data schema, since the function of BIM applications and fire simulation software is totally different. For examples, Fire Dynamics Simulator (FDS), as one of fire simulation tools widely used by fire engineers, developed by the National Institute of Standards and Technology (NIST) can analyze smoke and heat transport process and describe the evolution of fire [5]. Nevertheless, the current building modeling practice of FDS often starts with manual gathering of basic building geometry information and semantic information required for performing fire simulations from either paper documents or electronic documents, such as electronic computer-aided design (CAD) drawing files. And then input all of the information into FDS input data files to support software simulation. Therefore, the current fire modeling practices based on FDS input data files are highly time-consuming, cost-intensive, and error prone, especially for large-scale building, which does limit the further application of FDS. Thus, the data sharing between BIM applications and fire simulation software can help fire engineers avoid manually reinserting data in fire modeling practices, since the BIM model contains a high level of detail, both geometric and semantic information, such as spatial layout, properties of the materials, and other data which are required for performing fire simulations. However, the data schema of mainstream BIM applications and FDS is totally different, and the current information sharing between them is inefficient and error prone.

Therefore, this paper proposes a comprehensive approach for information sharing for building fire safety analysis between mainstream BIM applications and widely used fire simulation software has been successfully implemented, based on IFC and FDS. For this purpose, the main objectives of fire simulation analysis based on BIM technology in this paper are to

(1) Develop a framework for direct translation of geometrical and semantic building information between BIM applications and fire simulation software to help fire engineers avoid manually reinserting data in fire modeling practices

(2) Store fire simulation results into building information model for further information exchanging and sharing to support performance-based design of buildings, including structural fire-resistant design and evacuation design

The rest of the paper is organized as follows: Section 2 reviews related works in terms of the information sharing between BIM applications and fire simulation software. Section 3 presents our proposed methodology framework utilized for the IFC- and FDS-based information sharing for building fire safety analysis. Sections 4 and 5 present the proposed IFC- and FDS-based information sharing for building fire safety analysis framework, the capability of which of is validated by a case scenario in Section 6 . Conclusions and limitation in this paper are introduced in Section 7.

\section{Related Works}

2.1. Application of FDS for Building Fire Safety Analysis. The research on the use of mathematical fire modeling began in the early 1940's [6]. One of mathematical computer fire models is computational fluid dynamics (CFD), also known as field models [7]. FDS, as one of fire simulation tools widely used by fire engineers, developed by the National Institute of Standards and Technology (NIST) is a computational fluid dynamics model of fire-driven fluid flow which can analyze smoke and heat transport process and describe the evolution of fire [5]. The simulation accuracy of FDS has been verified by multiple experiments $[8,9]$. The simulation output data of FDS can be displayed by the visualization program Smokeview (SMV) [10].

However, the fire modeling practices based on FDS input data files are inefficient and error prone. Then PyroSim [11], a preprocessor for FDS, was developed for engineers to create building geometry model and select the relevant parameters required for a fire simulation. It is a graphical user interface for the FDS and integrates the Smokeview visualization program [12], which can be used as a visual graphic form program for fire engineers to construct the $3 \mathrm{D}$ building model. However, the function of creating $3 \mathrm{D}$ building model in PyroSim is inefficient and unfriendly, because PyroSim only has two main modeling methods: one is importing FDS input files; the other is importing CAD file formats, including $3 \mathrm{D}$ or $2 \mathrm{D} \mathrm{DXF}$ format to allow threedimensional elements to be manually positioned by tracing DXF lines. Although we can use DXF format files exported from Revit, the building elements relations and the topology relation between points and lines will be damaged and lost. Thus, using the original FDS input files to establish the building model can guarantee the integrity of building component and avoid loss of topology relation. The commercial software PyroSim as the interface for inserting the FDS input file can only be used for the visualization of simulation result and the settings panel for fire scenario conditions.

\subsection{Application of BIM for Building Fire Safety Analysis.} Development of Building Information Modeling (BIM) started in the early 2000s [13], based on the early 
computer-aided design (CAD) and 3D object-based parametric modeling, as a collaborative approach to design and construct buildings. BIM model contains a high level of detail, including both $3 \mathrm{D}$ geometric information and semantic information to support decision-making of a buildings' lifecycle. IFC, as an open international standard developed for BIMers, is an EXPRESS schema developed by the International Alliance of Interoperability (IAI), which has since changed its name to buildingSMART International. It is based on the EXPRESS language as a part of the Standard for the Exchange of Product model data (STEP) standard (ISO 103030), which facilitates the information interoperability and integration in the building industry.

Similar work investigating the use of BIM for building fire safety analysis has been conducted by several researchers. Zhang and Issa [14] have proposed a new method of BIM-based immersive serious gaming environment to provide an immersive emergency evacuation scenario for the evacuation performance evaluation of the building design, which extend the study of BIM in performance-based safety design. Cheng et al. [15] developed a BIM-based intelligent fire prevention and disaster relief system supporting the visualization of real-time and dynamic fire information in three dimensions to support the planning of fire safety and efficient evacuation. Mirahadi et al. [16] developed a framework, EvacuSafe, for evaluating the evacuation safety performance of buildings through the IFC-based integration of the BIM model and fire simulation tools. However, their research focuses on the path identification algorithm and egress routes related to building layout in BIM which only involves the coordinates of the $x$-axis and $y$-axis of components instead of the whole geometry information. Li et al. [17] proposed a BIM centered algorithm to achieve dual objectives of improving room-level localization accuracy, where BIM is used to provide the geometric information and a graphical interface for user interaction. As to the knowledge of the authors, the use of BIM for building fire safety analysis mainly focuses on the performance-based design of buildings combined with the power of immersive visualization of BIM, instead of data information sharing between BIM software and fire simulation packages, which reveals the importance and necessity of this study.

\subsection{Building Fire Safety Analysis Based on the Integration of} $B I M$ and FDS. Data sharing and exchange are still weak in the traditional interoperability between BIM applications and fire simulation software. The data sharing between BIM and FDS need to be based on IFC format file and FDS input file. However, the data schema of them is totally different, since the two schemas are designed for different purposes. IFC, as a standardized data structure for the storage of building information, is also proposed to solve the problem of data exchange between varieties of professional engineering software, since EXPRESS modeling language capable of containing and representing product and process data fulfilling the requirements of an entire industry defines concepts and attributes considered relevant and creates semantic relationships between them [18].
Similar work investigating the integration of BIM and FDS has been conducted by several researchers. Dimyadi et al. [18] have proposed a practical method for querying spatial data from IFC file by using BIMRL (BIM Rule Language) which has an efficient IFC data querying capability. Then, the required geometric representation information from an IFC file can be mapped into the data specification of the FDS input file. However, in this approach, only geometrical data can be imported. Nongeometrical IFC data such as thermophysical properties of materials could not be present, although it is also required for performing fire simulations. Spearpoint et al. $[16,19,20]$ developed a web-based FDS conversion tool and an IFC model parsing tool to convert building models created in Revit and ArchiCAD to FDS input data. However, this data mapping implementation is limited to basic building geometry and supports for neither complex building geometry, such as inclined and curved surfaces nor semantic information exchange, such as thermophysical properties of materials.

Overcoming the current limitations of IFC- and FDSbased information sharing for building fire safety analysis requires a more comprehensive framework for both geometric and semantic information sharing between them to support performance-based design of buildings, which will be described in this paper.

\section{Methodology}

Based on the study of background and related works, the proposed information sharing framework for building fire safety analysis based on IFC and FDS is as shown in Figure 1.

Firstly, the proposed framework can support direct translation of geometrical and semantic building information between BIM applications and fire simulation software. The data sharing between BIM and FDS needs to be based on IFC file and FDS input file, where major issues can be categorized as (1) geometrical building information sharing, including the translation of coordinate systems and geometry description information and (2) sematic information sharing, including material information, heat detectors, smoke detectors, ventilation system parameters, and simulation result data. Both geometrical building information and sematic information can be shared by this approach through the transformation of coordinate systems, outer database, and IFC file extension.

Secondly, the proposed framework can support fire simulation results storage based on building information model for further information exchanging and sharing to support performance-based design of building, including structural fire-resistant design and evacuation design, which is based on the Application Programming Interface (API) of Autodesk Revit.

\section{Geometrical Information Sharing between BIM and FDS}

The transformation of coordinate systems and geometry description method are two major issues in geometrical 


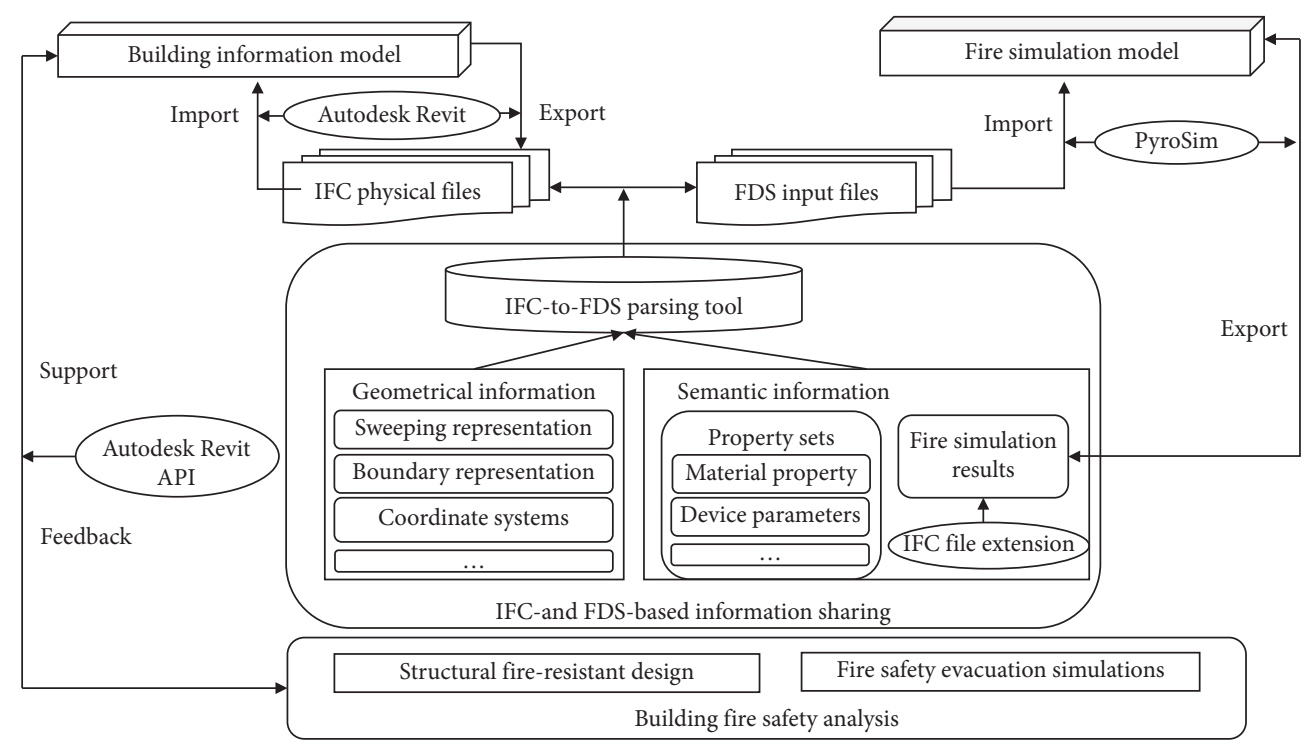

FIGURE 1: The framework of IFC and FDS-based information sharing for building fire safety analysis.

building information sharing between IFC and FDS. The FDS input files used in fire simulation containing parameters organized into name list groups provide all of the necessary information to describe the fire scenario and support fire simulation calculation, while BIM technology proposes Industry Foundation Classes (IFC) as an open and standardized data model to serve the BIM interoperability needs of the industry.

Parameters in FDS files are specified within the input file by using namelist formatted records [21], including input file header (HAED), simulation time (TIME), mesh parameters (MESH), miscellaneous (MISC), surface properties (SURF), material property (MATL), surface properties (SURF), obstruction (OBST), and device parameters (DEVC). Each fire scenario is defined within a three-dimensional computational domain consisting of rectilinear meshes. Since FDS approximates the governing equations on a rectilinear mesh, the geometry of the building is described by rectangular obstructions which are forced to conform to the underlying mesh. FDS input files use the name list group OBST to create obstructions mainly by defining the coordinates of the rectangular solid. The obstruction is defined by two points, which, respectively, are located at the end of the body diagonal of a rectangular solid, and each side of the obstruction must be parallel to coordinate axis. For example, "\&OBST $\mathrm{XB}=1.2,1.2,1.2,1.5,1.5,1.5 /$ " defines a rectangular solid with two diagonal points $(1.2,1.2$, and 1.2) and (1.5, 1.5, and $1.5)$, as shown in Figure 2.

The entire geometry of the building model is made up of approximate rectangular solids, and the modeling method is primarily determined by the fire simulation algorithm. The simulated domain is divided into small three-dimensional rectangular control volumes or computational cells. Each computational cell with some calculation parameters, including density, speed, species concentrations, and temperature, is calculated based on the mass, energy, momentum equation, etc. Therefore, FDS can predict smoke, temperature,

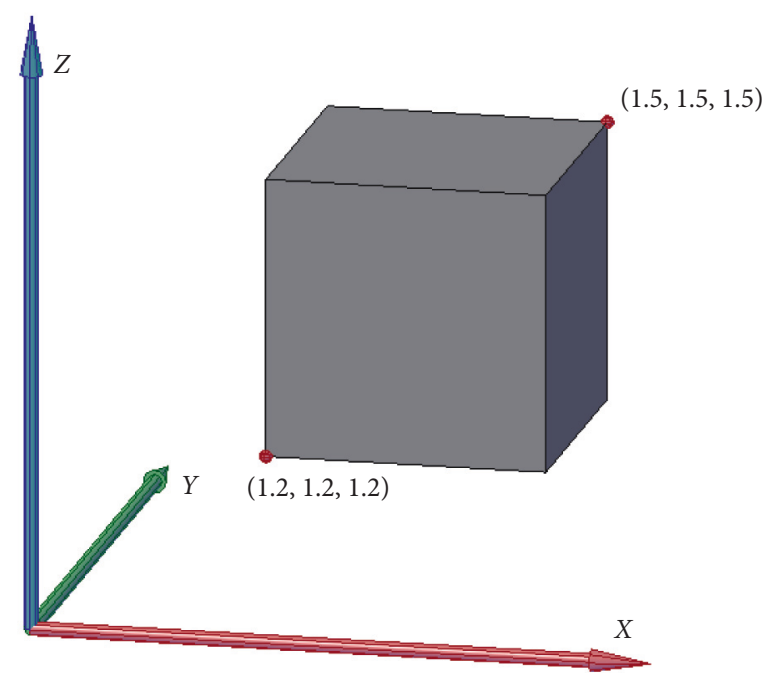

FIgURE 2: Obstruction positioned by two diagonal points.

carbon monoxide, and other substances during fires to solve practical fire problems and study fundamental fire dynamics and combustion.

The version of IFC used in this study is IFC2x 3 which we observe most in use for current mainstream BIM applications now. The IFC files use the entity type IfcSolidModel to represent the 3D shape by different types of solid model representations [22]. Its subtypes are CSG representation, sweeping representation, boundary representation, and other solid representation schemes. The entity inheritance relationship is as shown in Figure 3.

Researchers have launched initiatives to establish an approach to convert IFC data to FDS input data, especially Dimyadi et al. from New Zealand, who have made great achievements in this field [23]. However, their current conversion tool has a number of limitations $[1,24]$ : first, it cannot support Boundary representation geometry; second, 


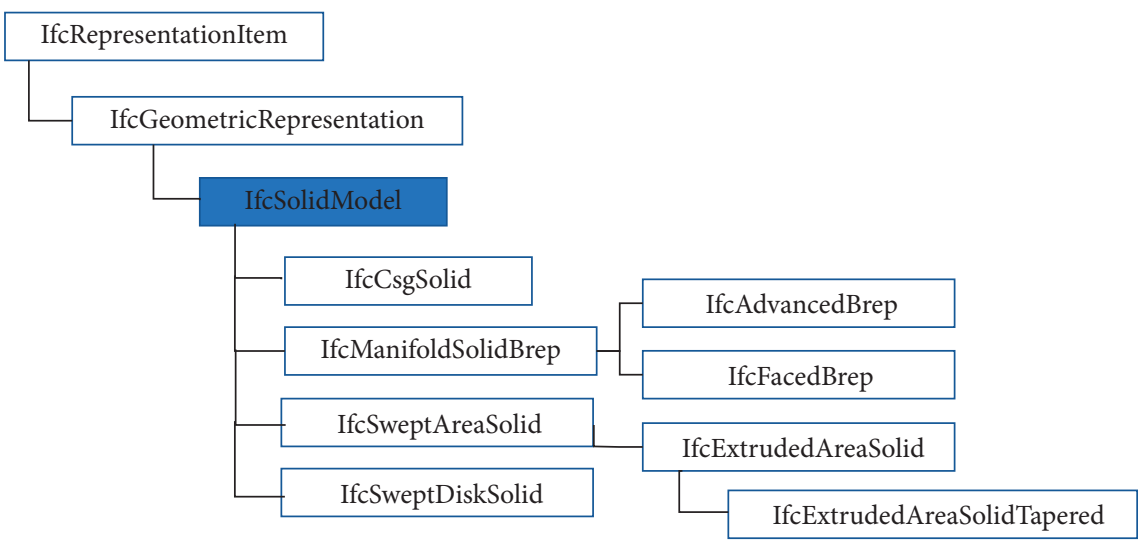

FIgURE 3: The IFC entity inheritance relationship.

only straight, orthogonal, and equal height building elements can be supported, and only single story buildings can be considered. In this paper, sweeping representation and boundary representation will be discussed more extensively to break those current limitations.

As shown in Figure 4, the two kinds of geometry modeling methods for a cone are greatly different. The cone entity represented by IFC data model uses the boundary representation model (Brep) in which closed surface is composed of several triangular patches. The cone expressed with FDS modeling method is divided into several small blocks. The size of those rectilinear blocks depends on the mesh configurations which have the significant influence on calculation accuracy and efficiency.

The IFC 3D shape representation, sweeping representation, and boundary representation are the common default geometry representation in IFC files. This section will describe the transformation of coordinate systems of these two geometry representation methods between IFC files and FDS files.

4.1. IFC Sweeping Representation Entity. Usually, building components are composed of regular geometrical objects, for example, the shape of beams, columns, slabs, and walls are cuboid. Therefore, the IFC data model often uses the sweeping representation entity, especially the IfcExtrudedAreaSolid entity allowing a two-dimensional planar cross section to sweep through space to generate these building components [25]. It has four attributes: ExtrudedDirection (determining the direction of the extrusion), Depth (defining the length of the extrusion), Position (determining the ordinate origin point of the extrusion), and SweptArea (defining swept area represented by a subtype IfcProfileDef).

This section will first solve the problem of geometry information transformation between FDS input file and IFC physical file which the building components are expressed by sweeping representation and swept area of the component is parallel to the $x-y$ plane in the global coordinate system. For components with the unparalleled swept plane or special shape, the boundary representation will be provided to realize information conversion in the next section.
4.1.1. IFC Space Coordinate Transformation. Different with the only global coordinate system used in FDS modeling process, IFC uses the local coordinate system to express swept solid geometry model. Therefore, the basic and essential requirement for geometry information conversion from IFC to FDS is to get the global coordinate for every point in FDS files whose position is defined in local coordinate system in IFC files.

The IFC uses entity IfcLocalPlacement to define the relative placement of a building element. This entity has two attributes: PlacementRelTo and RelativePlacement.

The attribute PlacementRelTo provides object reference function to establish the relation of two local coordinate systems to determine the absolute placement of the element in global coordinate system. The attribute RelativePlacement defines the information about local coordinate origin, the $z$ axis and the $x$-axis. In the \#168 statement, as shown in Figure 5, the origin of the coordinate system is at point $(-999.6,-1352.4,0)$ and the direction vectors of the $z$ - and $x$ axes are both null values, which means the axes of this local coordinate system are parallel to the global coordinate system. Then, according to the other local coordinates referenced by the PlacementRelTo entity, the absolute placement origin or the positional coordinate of this column can be determined accurately.

As shown in Figure 6, the $x^{\prime}-y^{\prime}$ coordinate is the local coordinate system and the $x-y$ coordinate represents the global coordinate. The conversion of the coordinate system can be completed by the coordinate formulas for transforming.

4.1.2. IFC Shape Information Extraction. The shape information is stored in the Representation Type. Then IfcShapeRepresentation with the inherited attribute Representation Type is used to define all shape-relevant information. It has four attributes shown as follows in braces. The first attribute describes the environment. The second attribute is representation identifiers for shape representation [19], like "Body" type in this case. The third attribute is representation types, like "SweptSolid" in this case, which means it is a swept area solid built by extrusion and revolution. The fourth attribute describes the storage relationship with other descriptive statements: 


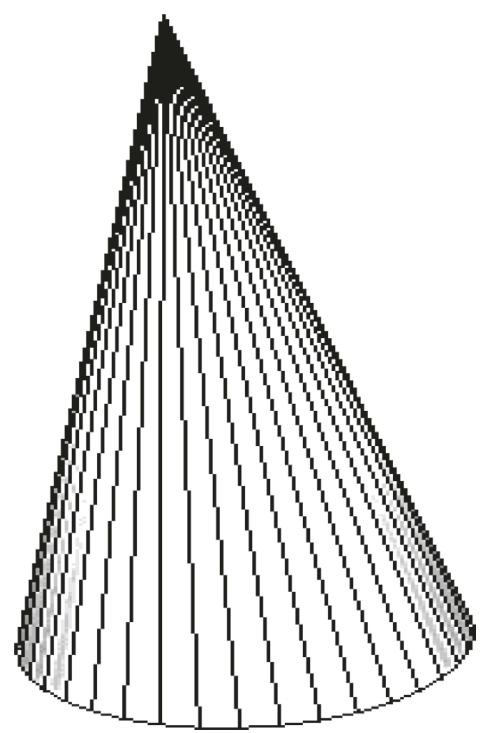

(a)

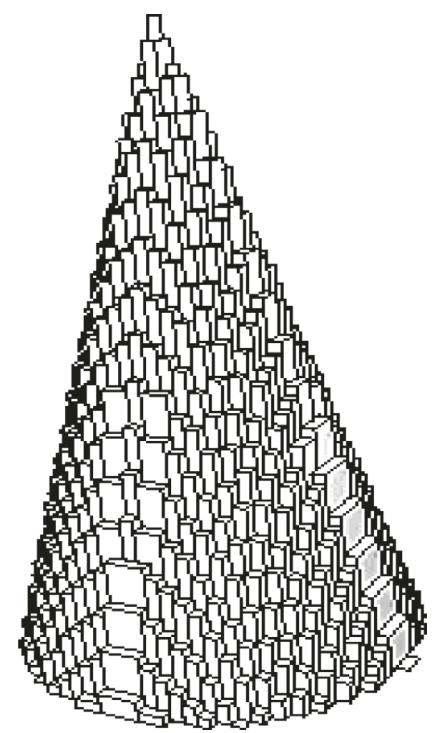

(b)

FIgURE 4: A cone expressed in the IFC data model and FDS model.
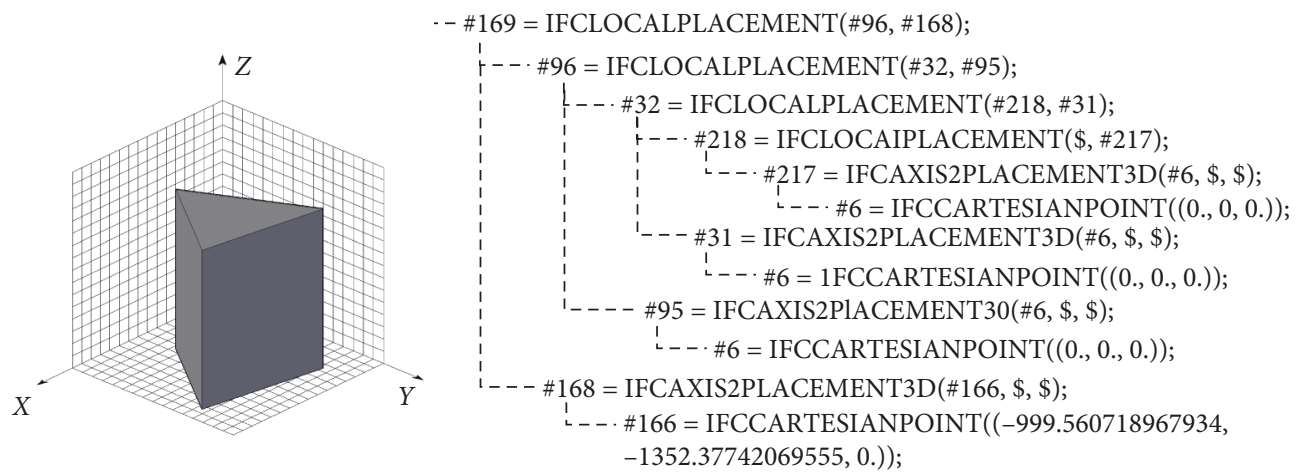

Figure 5: Swept solid geometry model.

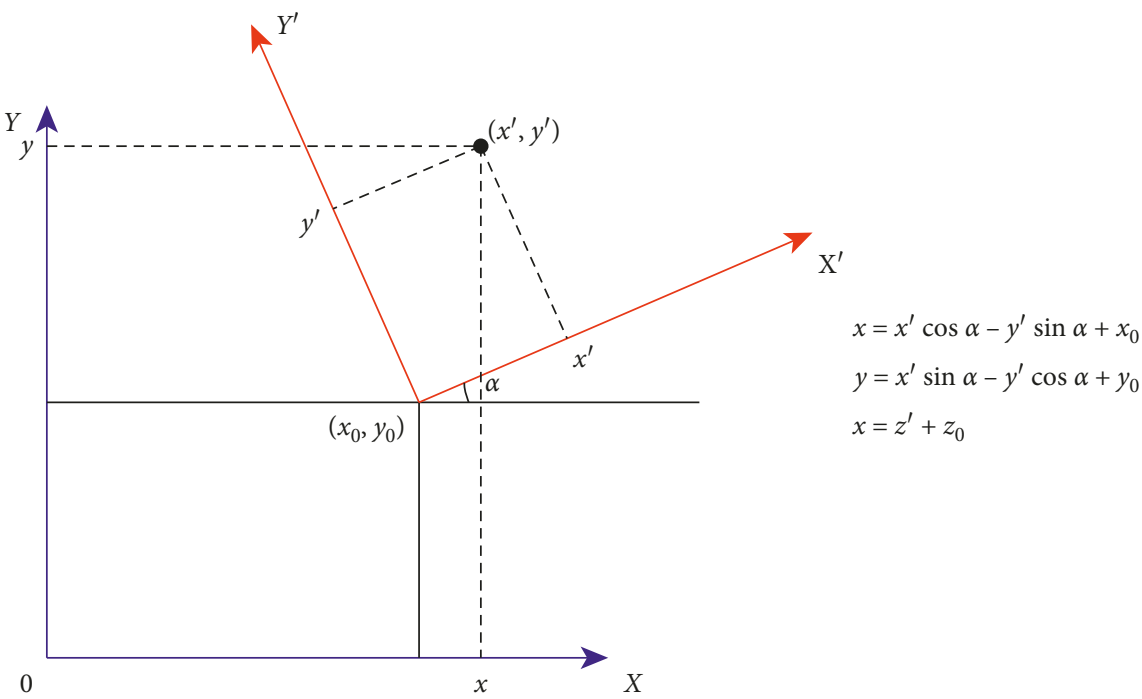

FIgURE 6: The transformation of coordinate systems. 


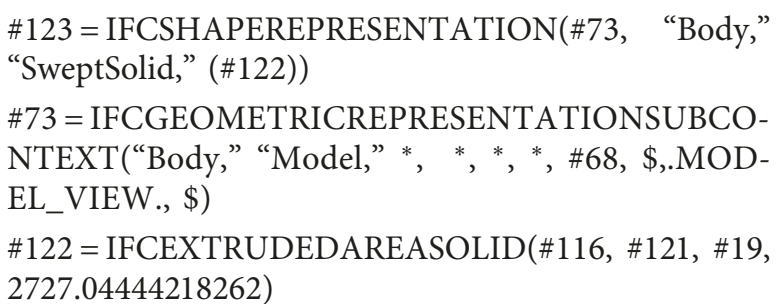

According to the above rule statement information, the detailed description of a swept solid can be found. As shown in the following IFC physical file, the records of an extruded area solid include its swept area, position, extrude direction, and depth. The swept area is closed by several polylines, which coordinate information is given by the IFCPOLYLINE entity:

$$
\begin{aligned}
& \# 122 \text { = IFCEXTRUDEDAREASOLID }(\# 116, \# 121, \# 19 \text {, } \\
& \text { 2727.04444218262) } \\
& \# 116 \text { = IFCARBITRARYCLOSEDPROFILEDEF(.ARE- } \\
& \text { A., " } \backslash \mathrm{X} 2 \backslash 65 \mathrm{CF} \backslash \mathrm{X} 0 \backslash 2 \text {," \#114) } \\
& \text { \#114 = IFCPOLYLINE((\#108, \#110, \#112, \#108)) } \\
& \# 108 \text { = IFCCARTESIANPOINT }((-781.301086027169 \text {, } \\
& -628.610820508116) \text { ) } \\
& \text { \#110 = IFCCARTESIANPOINT }((838.698913972831 \text {, } \\
& \text {-628.610820508116)) } \\
& \# 112 \text { = IFCCARTESIANPOINT }((-57.3978279456615 \text {, } \\
& \text { 1257.22164101623)) } \\
& \text { \#108 = IFCCARTESIANPOINT }((-781.301086027169 \text {, } \\
& \text {-628.610820508116)) } \\
& \text { \#121 = IFCAXIS2PLACEMENT3D (\#117, \#19, \#119) } \\
& \text { \#117 = IFCCARTESIANPOINT((531.9846459992552, } \\
& -92.0883098110122,3) \text { ) } \\
& \# 19=\operatorname{IFCDIRECTION}((0 ., 0 ., 1 .)) \\
& \# 119=\text { IFCDIRECTION }((0.529919264233206 \text {, } \\
& 0.848048096156425,03)) \\
& \text { \#19 = } \operatorname{IFCDIRECTION}((0 ., 0 ., 1 .))
\end{aligned}
$$

Therefore, after extracting the shape information and transforming coordinate systems, all geometrical model information in the global coordinate system can be determined.

4.1.3. IFC Information Translation for FDS. A conversion tool primarily written in C\# using the Microsoft. NET environment is developed to transfer building geometry information from IFC data model to FDS simulation model. The conversion process can be divided into three steps: firstly, mesh the contour of swept area, then describe the swept area with rectangular obstructions, and finally, convert the entire geometry of extruded solid into a series of orthogonal rectangular smaller solids.

The key requirement of the method to mesh the contour of swept area is to find the meshes which intersect the border line. The first step of algorithm is cutting the boundary line into several sections along the $x$-axis. The projection of each section along the $x$-axis is the side length of a single grid cell.
Then, the grids where division points are located in are obtained as an intersecting grid. After the same operation takes place along the $y$-axis and the repeated part of the grid obtained in both $X$ and $Y$ directions removed, the remaining grids are obtained as the boundary grids, as shown in Figure 7.

After meshing the contour of swept area, the inner area also needs filling with grids, as shown in Figure 8. The lower and upper bounds of the inner area can be determined by the vertex coordinates of the boundary line.

Next, according to the extrude direction, the depth, and the center point of the swept surface obtained via the geometric shape extraction, the central axis of the extruded solid can be determined and divided into several sections along the $z$-axis. The length of each section projected along the $z$-axis is regarded as the cell height. As shown in Figure 9, the line $\mathrm{AB}$ is divided into 14 parts. The 13 division points are regarded as the center of each layer to copy the swept area and form the entire swept solid.

Base on the above steps, the entire geometry of extruded solid described in the IFC data model can be converted into FDS obstruction description. This kind of conversion process can support any form of geometry components expressed by the IfcExtrudedAreaSolid entity in the IFC data model, even for solids with arbitrary boundary shape or extrusion direction no-perpendicular to $x-y$ plane as shown in Figure 10.

4.2. IFCBoundary Representation Entity. There are a number of challenges when creating building models which have a complicated architecture form, varied curvy shape, or special-shaped components in FDS because of the modeling rule of orthogonal rectangular obstructions. In the IFC data standard, the Boundary Representation (Brep) property is given as a description of special-shaped components.

Boundary Representation defines solids with complex surfaces by a limited number of bounding polygons, i.e., the complex surfaces are divided into a number of small patches to emulate the shape of the components and form a closed solid. Thus, the Boundary Representation type is a very common way to support description for any geometry. The specific information can be obtained from the attributes of the IfcFacetedBrep entity, which stores the data relative to bounding polygons.

For example, a triangular patch $\mathrm{ABC}$ in the IFC data is shown in Figure 11; the expression of this triangular segment in FDS model is using rectangular obstructions which are forced to conform to the underlying mesh. Thus, the smallest cuboid which can cover this triangular patch needs to be found firstly.

According to the vertexes of the triangle, the smallest cuboid can be determined, as shown in Figure 12.

After meshing the cuboid and forming the surfaces of the solid, there may be some inner cavities need to be filled with the obstruction blocks. A special curved roof is shown here as an illustration of the capability of this kind of conversion process [21], as shown in Figure 13.

However, it is obvious that, in large-span space structures, the expression of curved roof using IFC Boundary 


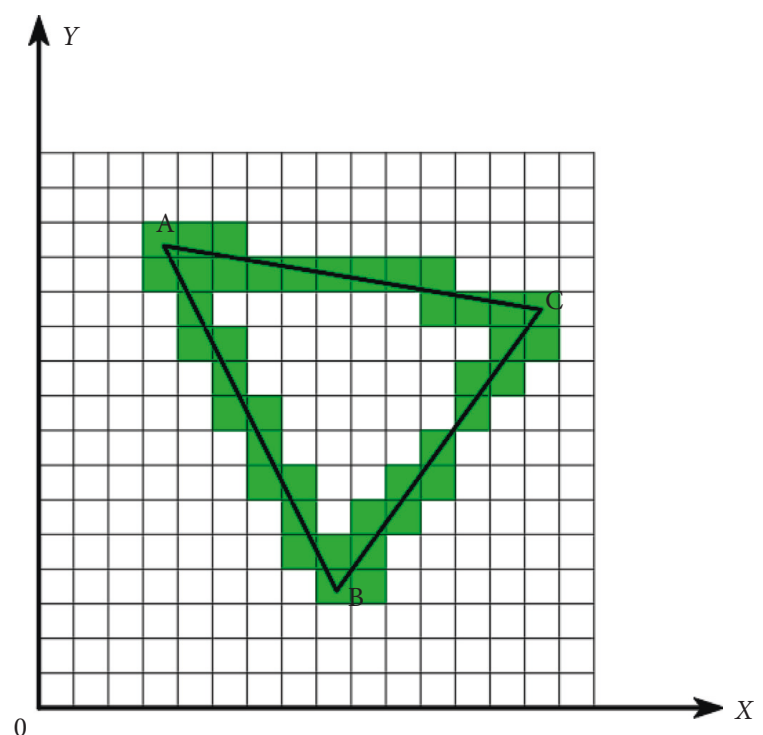

Figure 7: Meshing boundary lines.

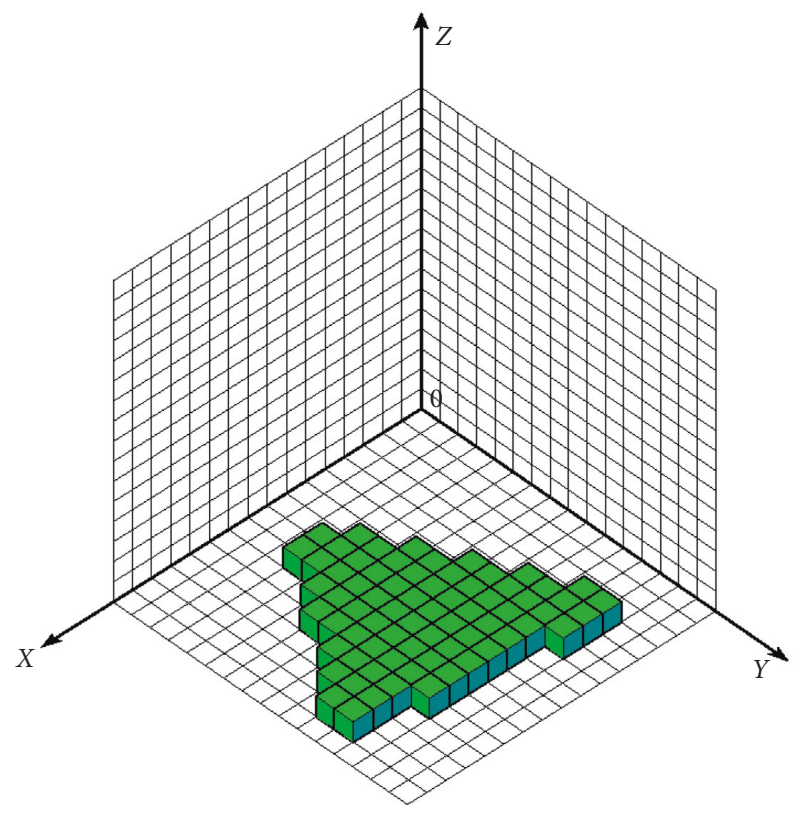

FiguRE 8: OBST representation for SweptArea.

Representation is often composed of triangles with larger dimensions. Therefore, the geometry simulation accuracy will be greatly reduced in this situation. The improved approach is to divide the triangular facets into smaller triangular patches, i.e., proceed the second division, as shown in Figure 14. The triangle is divided into six smaller triangular patches via using the centroid of the triangle. Then, each triangular patch will be matched with its smallest cuboid, respectively.

After the second division, the curved roof mentioned above is shown as Figure 15, and it is much more accurate than the entity shown in Figure 13.

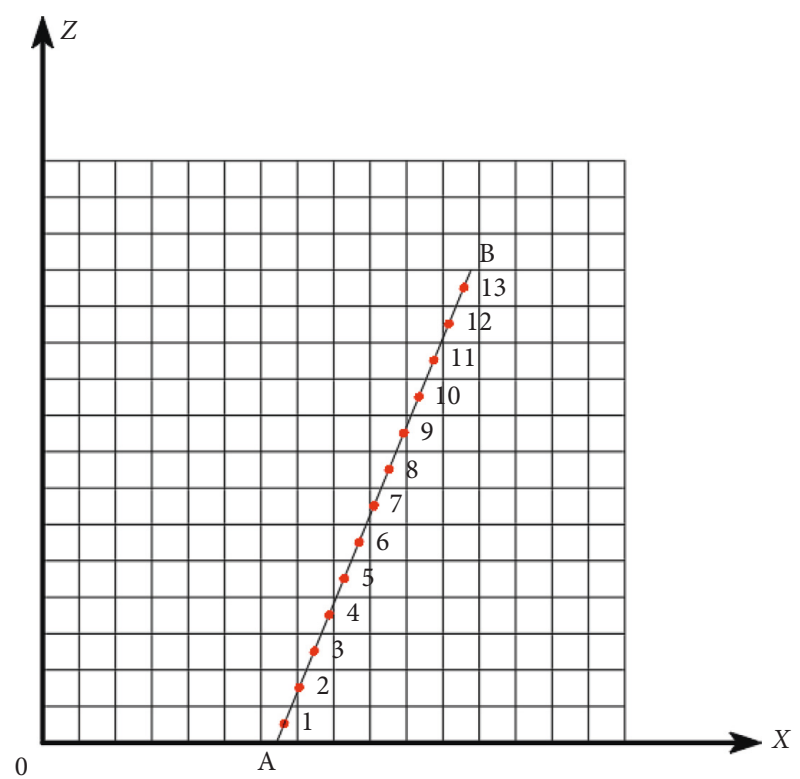

Figure 9: Divide the central axis.

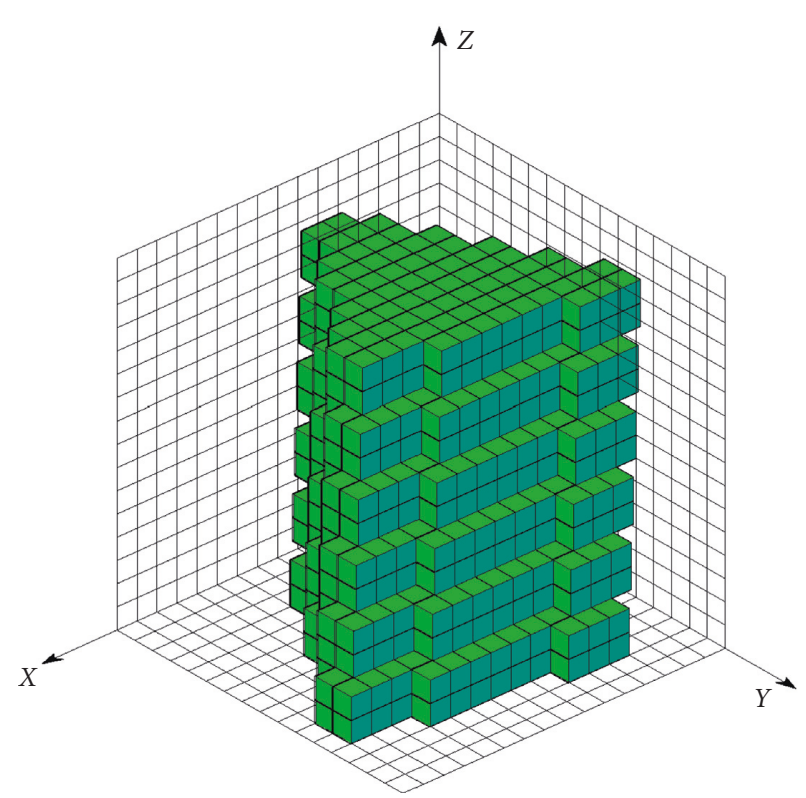

FIGURE 10: OBST representation for swept solid.

\section{Semantic Information Sharing between BIM and FDS}

The BIM model contains not only three-dimensional representations of buildings but also a high level of sematic information detail as well, such as fire properties of the materials and other data which must be required for performing fire simulations. The information sharing of this kind of properties can help fire engineers avoid manually reinserting data for setting an FDS input file.

However, recent data sharing implementation is limited to basic building geometry, which cannot support for 


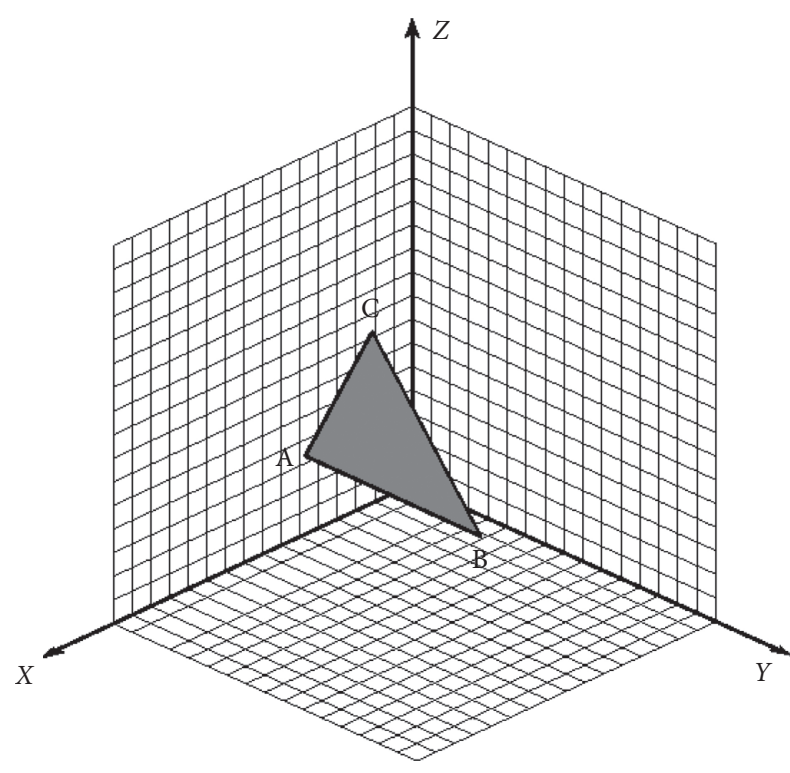

Figure 11: Triangular patch.

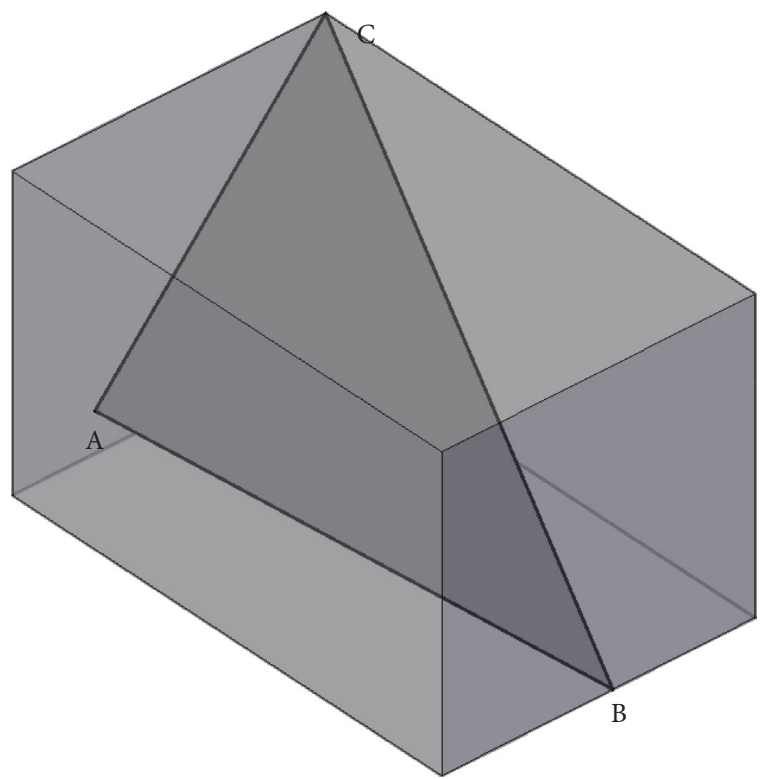

Figure 12: The smallest cube contained triangular patch.

semantic information exchange, including thermophysical properties of materials, heat detectors, smoke detectors, ventilation system parameters, and simulation result data. For example, since FDS input files use the outer material database to record basic description and combustion reaction of the material, the IFC data standard records the property of the material by some IFC material-related entities, which are totally different.

In this paper, the IFC data file and FDS input files are used to support direct and efficient information transformation between the BIM applications and the fire simulation software to break the barriers of "information islands." The content automatically written into FDS input files before fire simulation analysis and written into IFC files

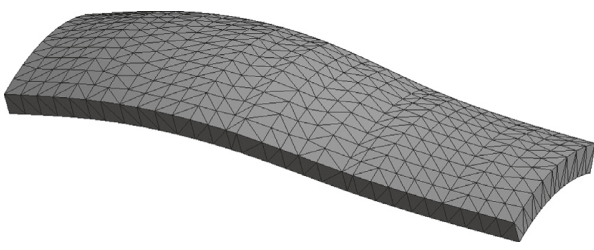

(a)

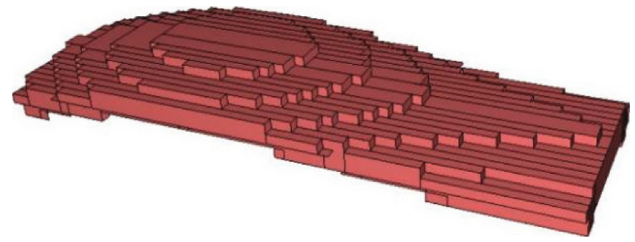

(b)

FIGURE 13: The curved roof models.

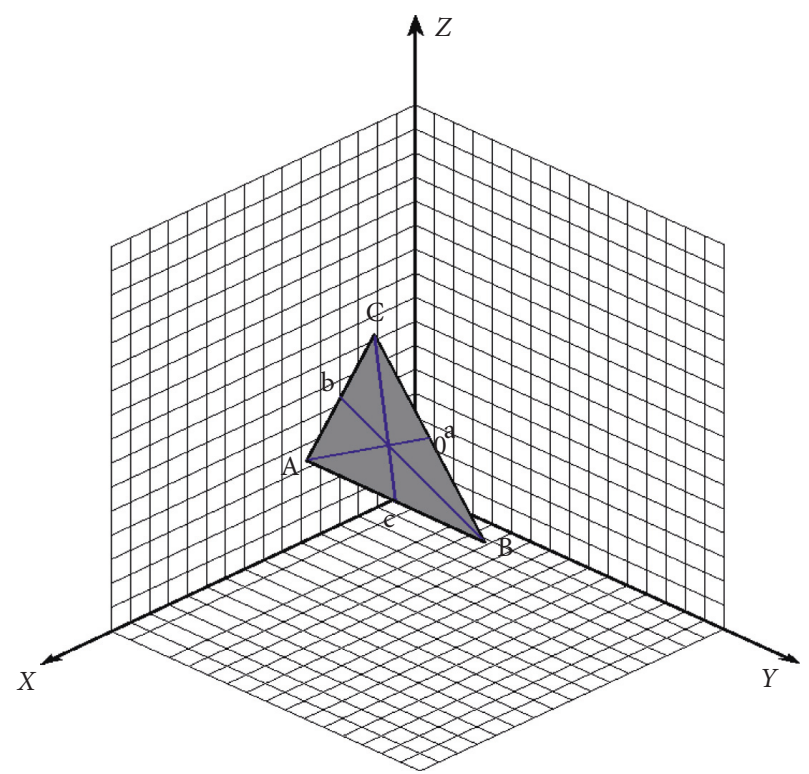

FIgURE 14: Subdivided triangular patch.

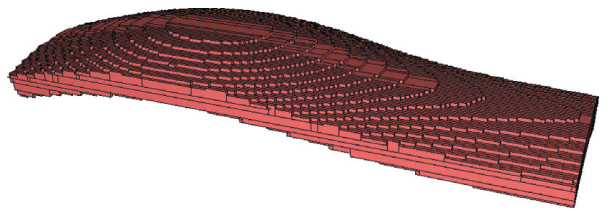

FIgURE 15: The optimized roof model.

after fire simulation analysis by the conversion program includes both geometrical and sematic information, such as input file header, mesh parameters, surface properties, material property, obstruction, and mainly device parameters which are required in an FDS input file and fire simulation results which can be stored in IFC file by expanding the IFC types and entities.

5.1. From BIM to FDS. The issue of material information conversion is solved by using outer material database. The 
outer material database referenced to FDS material library contains basic description and combustion reaction of the material. The IFC data standard records the property of the material by the IfcMaterial property. And every element uses the IfcRelAssociatesMaterial type to establish the contact with the IfcMaterial property and defines their material. The process is shown in Figure 16. First, obtain the IfcMaterial property from the IfcBuildingElement entity. Then, search the material in outer material database and write the information relevant to fire simulation into FDS files using the name list SURF_ID, REAC FUEL, and MATL_ID. Thus, material information sharing can be realized by using the outer material database. It will save the cost and time spent on assigning material to the components surfaces in the FDS modeling process.

The ability to create ventilation entities in the BIM model has potential downstream effects on the availability of those entities and their mapping to fire simulation model. The BIM model often has the entire HVAC system which is closely related to the fire simulation analysis. In IFC standard, the IfcDistributionElement entity is provided to descript all elements which participate in a distribution system, containing cooling system, heating system, ventilation system, and plumbing system. Therefore, the ventilation system can be read from IFC files and written into FDS files by using velocity boundary conditions.

For example, a supply or exhaust fan in a BIM model can be described in the FDS model as a VENT on a solid surface and designate a SURF_ID with specified velocity flow rate, as shown in Figure 17. In addition, our parsing tool can automatically identify some measurement point which needs recording some quantity of the simulated environment, like a thermocouple recording the change of temperature at one point. And, it can designate them into FDS files via the name list group DEVC.

After fire simulation in FDS, the key result data can be stored in IFC physical files by IFC expansion mechanism. And, it can be displayed in Revit by parsing tool developed by Revit API.

5.2. From FDS to BIM: IFC Expansion for Storing Fire Simulation Results. Most data are obtained from fire simulators or other simulators that cannot yet be contained in the IFC Data Model. But, the IFC data standard supports to add new object/attribute/relationship sets to the IFC data model to allow the inclusion of such data [25]. The approach of data storage and sharing about this information can be based on outer database and the IFC file extension.

The fire simulation information includes basic description of the fire scenario, temperature profile, heat flux and mass flow rate, particle output quantities, and other firerelated data. A specific example of a beam component will be used here to describe the method of expanding IFC entities relative to FDS simulation information.

The IFC data standard as an open data exchange format has a strict and clear organizational framework and data structure [26], as shown in Figure 18. Usually, the IfcProperty entity can be used to capture the properties defined by any users and associate them automatically with the related objects recorded in IfcBuildingElement entity by the IfcRelationship inverse attribute.

The IfcProperty entity has a subtype named IfcPropertySingleValue which can define the property with a single numeric or descriptive value. Take several fire simulation information as an example which is shown as follows:

$$
\begin{aligned}
& \text { \#181 = IFCPROPERTYSINGLEVALUE ("FireScene," } \\
& \text { \$, IFCTEXT (“( } 31,46,0) ; 3 ; 500 ; 0.04689 ; 179 ; \mathrm{t} 2 ”), \$ \text { ) } \\
& \text { \#182 = IFCPROPERTYSINGLEVALUE (“TimeInterval," } \\
& \text { \$, IFCTEXT (“0.5; } 0.5 ; 0.5 ; 0.5 ; \ldots ; 0.5 ”), \$ \text { ) } \\
& \# 183 \text { = IFCPROPERTYSINGLEVALUE ("Measur- } \\
& \text { ingPoint,” \$, IFCTEXT (“(10, 0, -1); }(10,1,-1) ;(10,20 \text {, } \\
& \text {-1) }(10,40,-1) 2 \text { \$”) } \\
& \text { \#184 = IFCPROPERTYSINGLEVALUE (“Temper- } \\
& \text { atureChange,” \$, IFCTEXT (“ } 1 ; 20 ; 20 ; 21 ; 22 ; . . ; 450 ”) \text {, } \\
& \text { \$) }
\end{aligned}
$$

The \#181 statement describes the basic fire simulation information. The first value indicates that this command line records a fire scenario named as "FireScene." And, the fire source's position is at point $(31,46,0)$. The second value points out that the fire area is $3 \mathrm{~m}^{2}$. The third value is the heat release rates per unit area which is $500 \mathrm{~kW} / \mathrm{m}^{2}$. The other values are followed by fire growth coefficient $\left(\mathrm{kW} / \mathrm{s}^{2}\right)$, fire growth time (s), and fire growth model.

The \#182 and \#183 statements define the time interval and location information related to devices, which record some quantity of the simulated environment, like a thermocouple or a smoke detector [21]. The \#184 statement records the information of temperature variations which has a one-to-one correspondence with devices. And, these attribute sets can be expanded if there are new attributes needed to adding.

Then, the above properties will be grouped in the fire simulation attribute set, as shown in the \#190 code. Finally, associate the attribute set with the relative component, as shown in Code \#195. For example, in this case, they are associated with the \#171 element:

$$
\begin{aligned}
& \text { \#190 = IFCPROPERTYSET (“1M3DIiSTb9AucRq2_- } \\
& \text { VoiSr, \#41,” “IX2\9650523667614EF6 XXO),” \$, (\#181, } \\
& \text { \#182, \#183, \#184)”) } \\
& \text { \#195 = IFCRELDEFINESBYPROPERTIES (“1hAXM- } \\
& \text { BYGT1Kw9_LNXJByBV, \#41, \$, \$, (\#171), \#190”) }
\end{aligned}
$$

In conclusion, it can complete the storage of the fire simulation information in the IFC data model by expanding the IFC types and entities. And, based on the Application Programming Interface (API) of Autodesk Revit, the visualization of fire simulation results in BIM applications by reading from IFC data files can be displayed in Autodesk Revit platform, which will be illustrated in the next section.

\section{Case Scenario}

6.1. IFC- and FDS-Based Information Sharing. In order to illustrate the capability of this transform mechanism and the feasibility of expansion of IFC model for fire simulation 


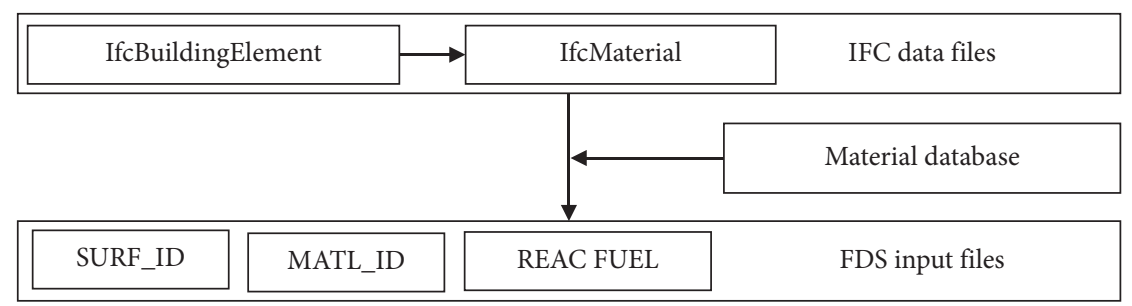

Figure 16: Material conversion method.

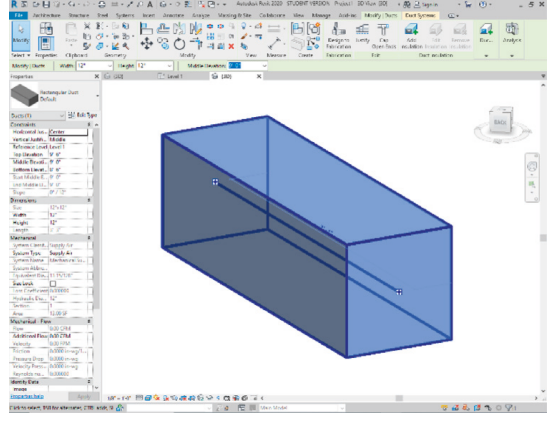

(a)

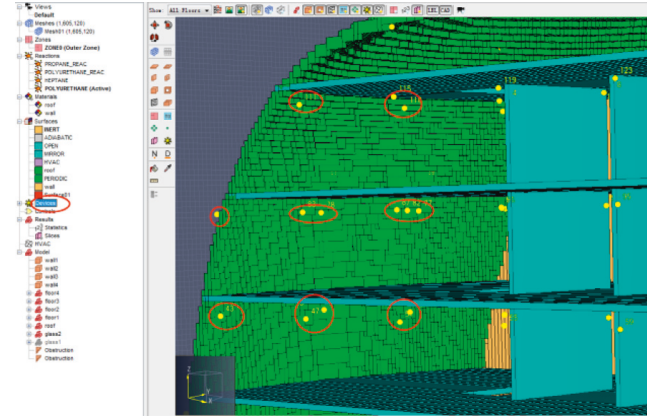

(b)

FIgURE 17: (a) The ventilation in Revit building model. (b) The thermocouple in FDS model.

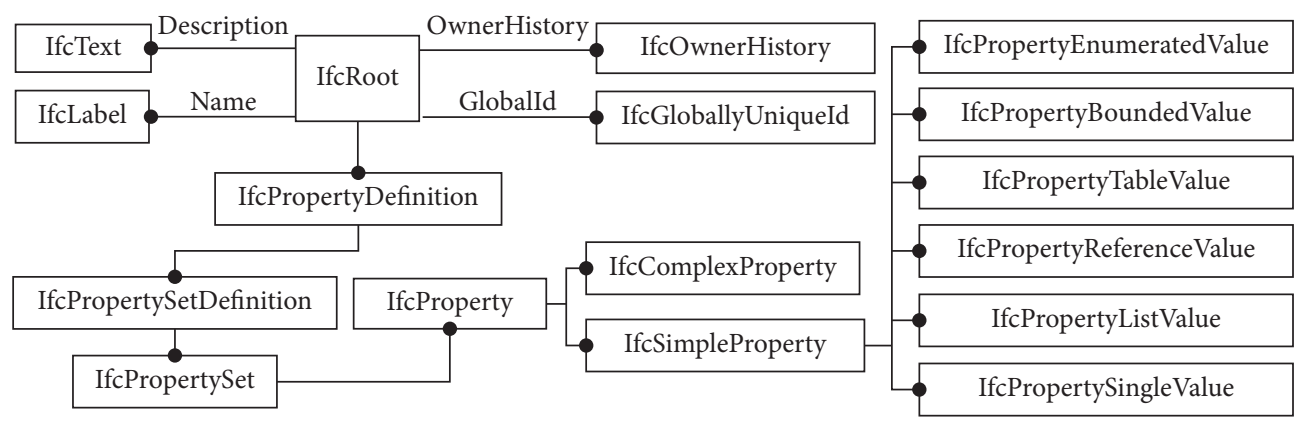

FIGURE 18: Inheritance definition of IfcProperty.

information, a gymnasium has been taken as a case study. Autodesk Revit 2014 is adopted as the virtualization platform for building information model and fire simulation results stored in IFC data files by the IFC file extension [27]. Autodesk Revit is one of the most popular BIM software, which includes three modules: Revit Architecture, Revit Structure, and Revit MEP, and together they form a complete design process based on the building information model. In addition, Autodesk Revit also offers an Application Programming Interface (API) designed to allow external application developers to integrate their applications with Autodesk Revit. Since Revit provides fully certified IFC import and export, model built in Revit can be stored as IFC data standard to support information storage for a building life circle. Therefore, in this case, both the data parsing tool and visualization function are developed by Autodesk Revit and its API.

The conversion process between BIM building model and FDS fire simulation model is as follows: first of all, the building information model of the gymnasium is established in a Revit template, which can provide a quicker and more convenient modeling scheme compared with FDS traditional modeling method. Then, output the IFC data file and convert it to the FDS input file via the conversion tool. Next, import this existing FDS input file into PyroSim to check the validity of each record and complete the FDS building model modeling process automatically and efficiently. From the comparison between Revit building model and FDS building model, as shown in Figure 19, it is obvious that geometry information can be converted successfully from IFC data model to FDS files by this way.

In this case, simulation results data are associated with its relative building components as a convenience to the users to search information by clicking the building components. As shown in Figures 20 and 21, there is relevant simulation data and diagrams of temperature change near a window and visibility near a door. Therefore, the BIM model containing fire simulation analysis results can be gained successfully. 


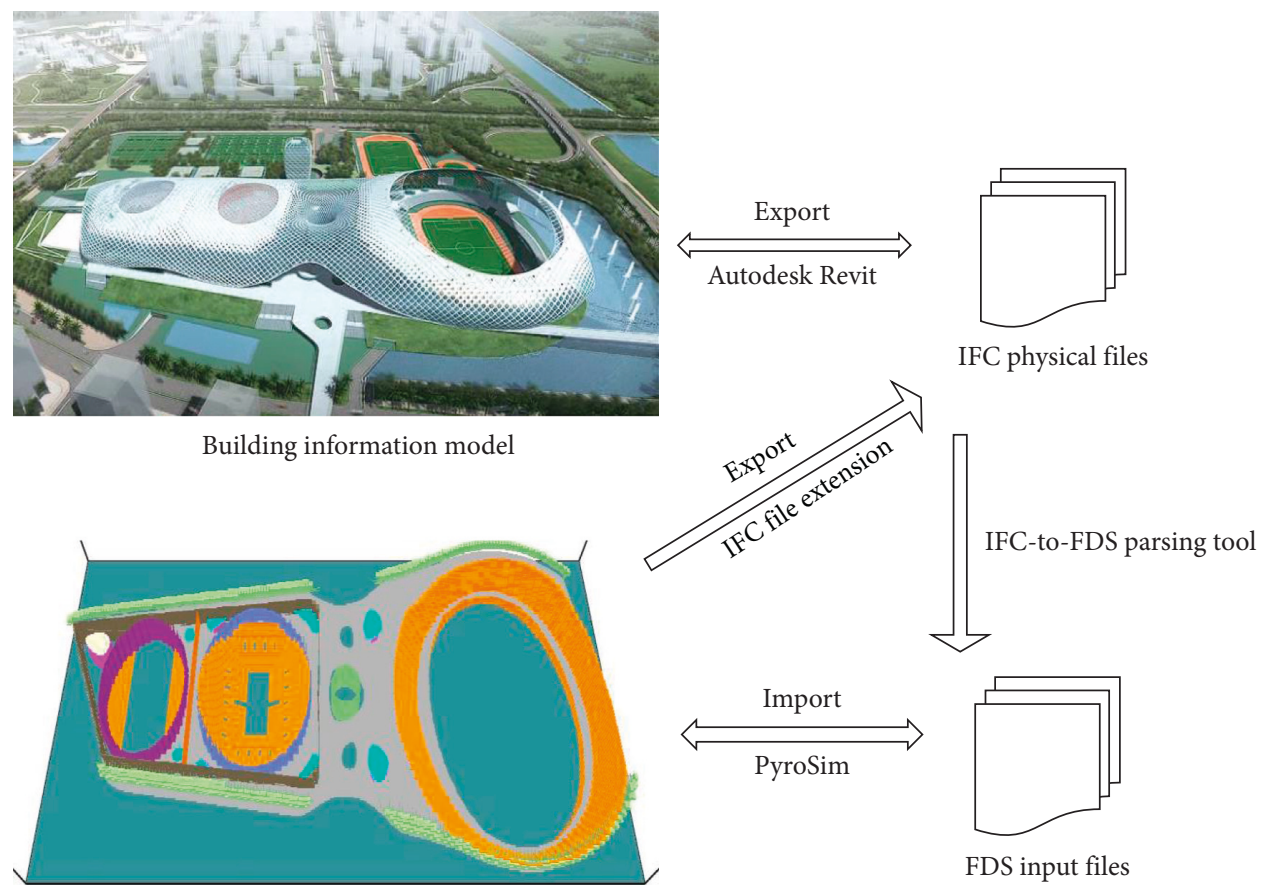

Fire simulation model

Figure 19: IFC- and FDS-based information sharing.

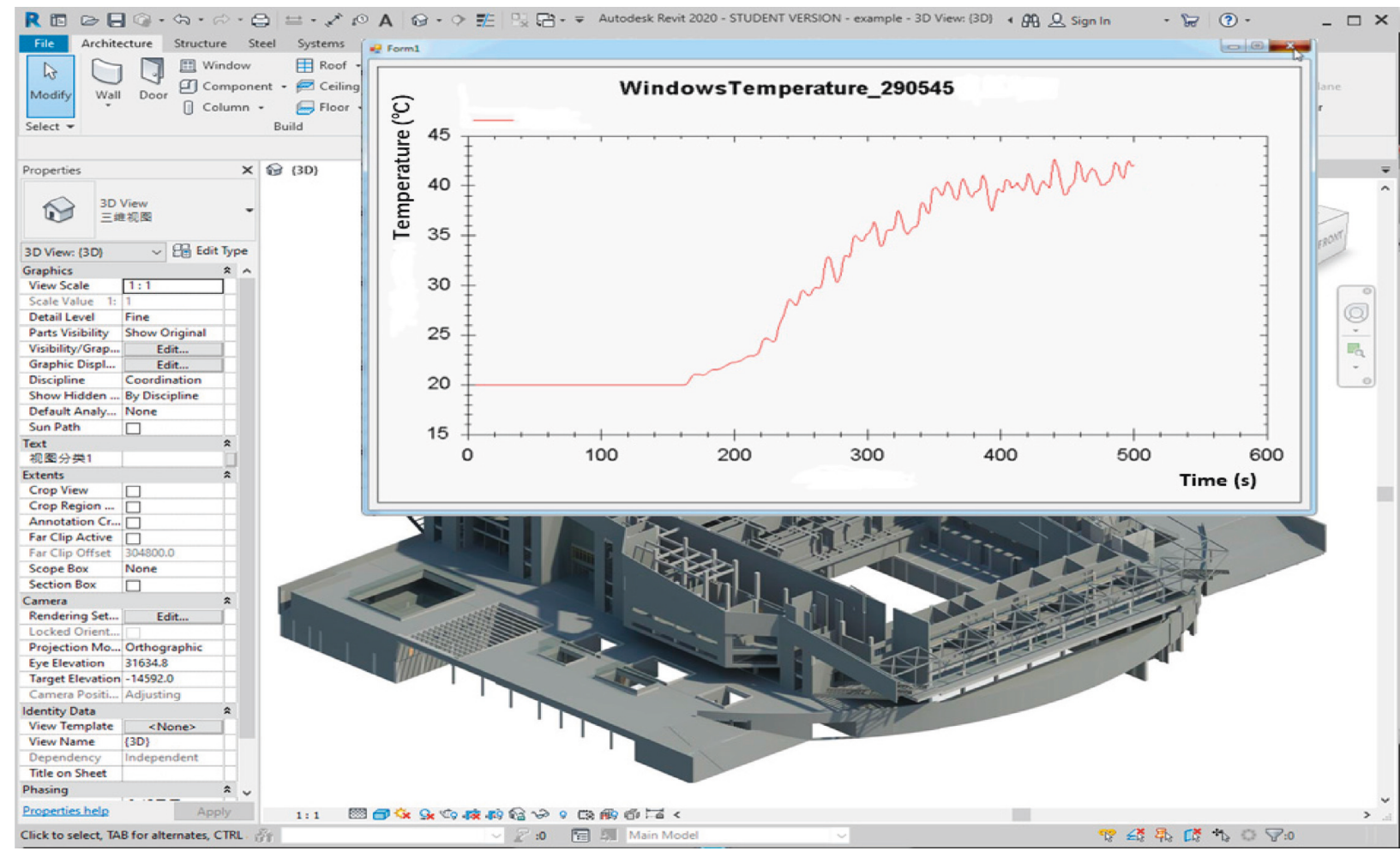

Figure 20: Data and diagrams of temperature change near a window.

6.2. Building Fire Safety Analysis Based on Unified BIM Model. It is a basic functional requirement that the structure remains stable to allow enough time for safe evacuation and rescue under real fire conditions. Therefore, structural fire- resistant design must integrate evacuation and fire interactions models. However, traditionally, fire safety design is still widely performed separately in specified individual study domains, such as fire engineering and structural 


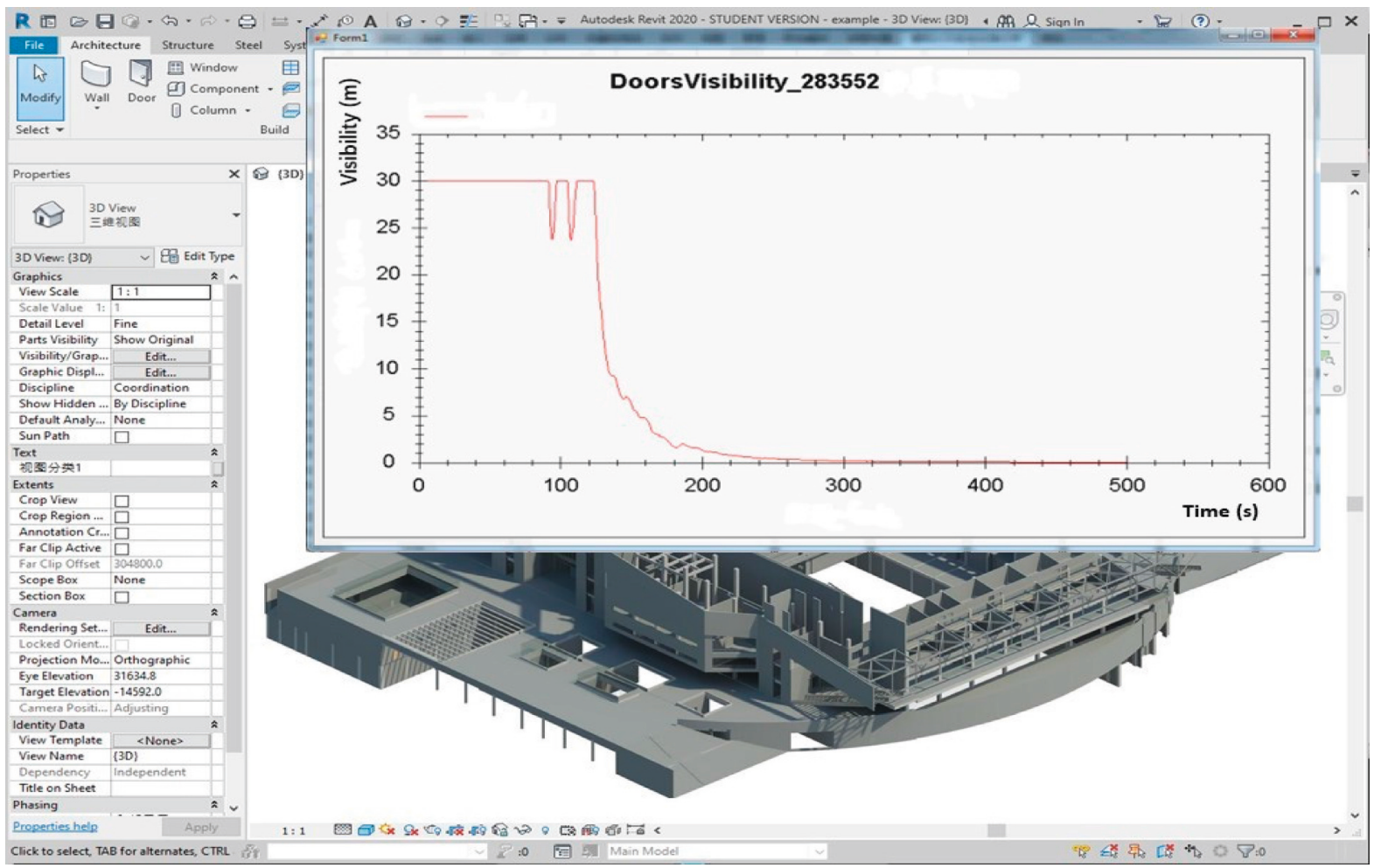

Figure 21: Data and diagrams of visibility near a door.

engineering. The impacts of a real fire have not been considered in structural fire-resistant design and in evacuation simulation.

In this paper, the BIM model containing fire simulation results can support optimization of the building performance-based design, including structural fire-resistant analysis and evacuation simulation of occupants under real fire condition [28, 29]. The effects of a natural fire on structures and evacuation can be simulated and analyzed through the unified BIM model, rather than using assumptive fire condition or ignoring fire as what previous works did. One part of the selected gymnasium has been taken as a case study of the application of the BIM model which stored the fire simulation information.

6.2.1. Structural Fire-Resistant Design. Structural fire-resistant design is a significant content of fire safety evaluation of buildings. It is extremely important to identify those members which may result in the collapse of the whole structure under fire conditions $[30,31]$.

The building studied is a circular gymnasium with a largespan covering an area of $12,000 \mathrm{sq} \cdot \mathrm{m}^{2}$ and an overall height of $36.5 \mathrm{~m}$ from the top to the ground (as shown in Figure 22). The roof structure of the gymnasium is supported by 288 radial prestressed steel cables with a diameter of $50 \mathrm{~mm}$ in two layers, namely, 144 cables in each layer. In the center of the roof, there exists a circular steel space truss structure that supports both the upper and lower sets of cables. The outer ends of all cables are anchored in concrete beams and columns around the building (as shown in Figure 23).
By running data conversion interface between BIM model and structural analysis model, the results of FDS simulation and structure analysis information in BIM model can be transformed and imported into ANSYS by Revit API. All structure analysis information in IFC files is represented by the IfcStructuralAnalysisModel entity, as shown in Figure 24. These fire simulation results were then taken as the boundary condition which is applied to the structural analysis model due to thermal transfer into the gymnasium structural members.

Based on finite-element analysis under thermal action, the temperature field history within the steel structure could be obtained. The thermal effects on the structural elements were treated by subdividing the steel structure into a number of uniaxial heat transfer elements. Heat conduction, nodal temperatures, and heat flow rate are calculated on the basis of the heat transfer elements.

The structural response analysis was then carried out using a 3D link finite-element to model the steel cable structure. The analysis was first carried out on the steel cable structure at ambient temperature. Under the service load of $7.5 \mathrm{kN} / \mathrm{m}^{2}$, the center deflection was $27 \mathrm{~mm}$, which is less than span/300. The maximum tensile force reached about $64 \%$ of the ultimate load carrying capacity. The structure was well designed to satisfy both the ultimate and serviceability limit states at ambient temperature.

By further coupled thermal-structural analysis, the safety status of the steel structure due to fire was evaluated. Figure 25 shows the displacements of the roof s steel structure under two different thermal loads at peak time. Figure 26 compares the stresses in the steel roof structure under 


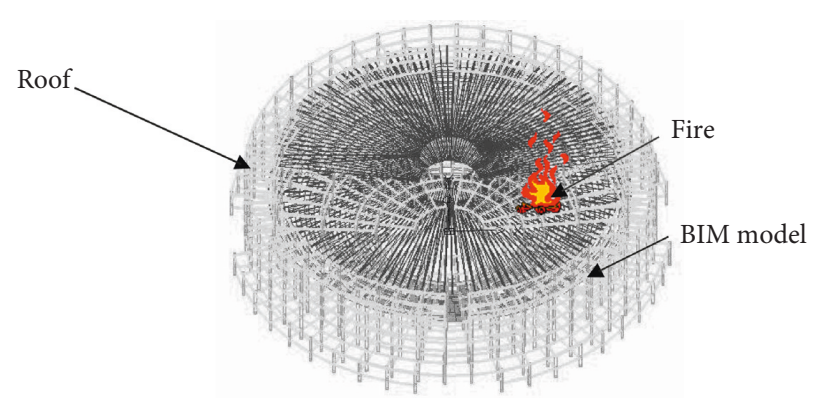

Figure 22: The building model and plan.

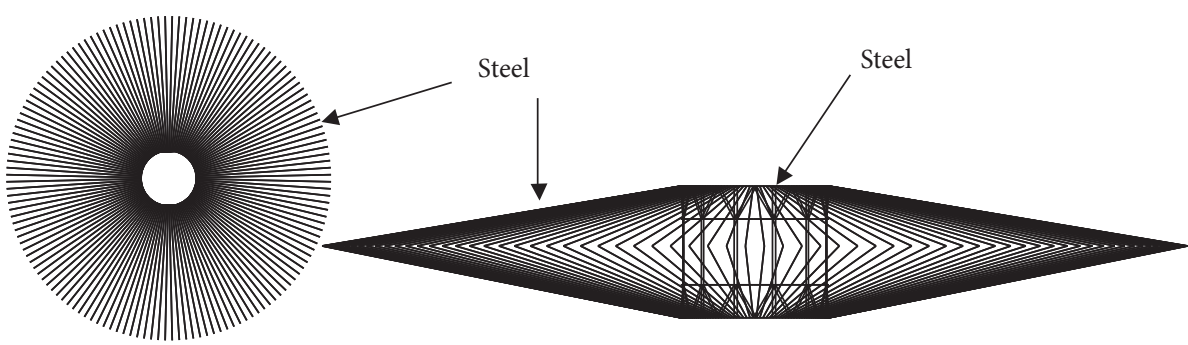

(a)

(b)

Figure 23: Roof structural view. (a) Top view. (b) Side elevation.

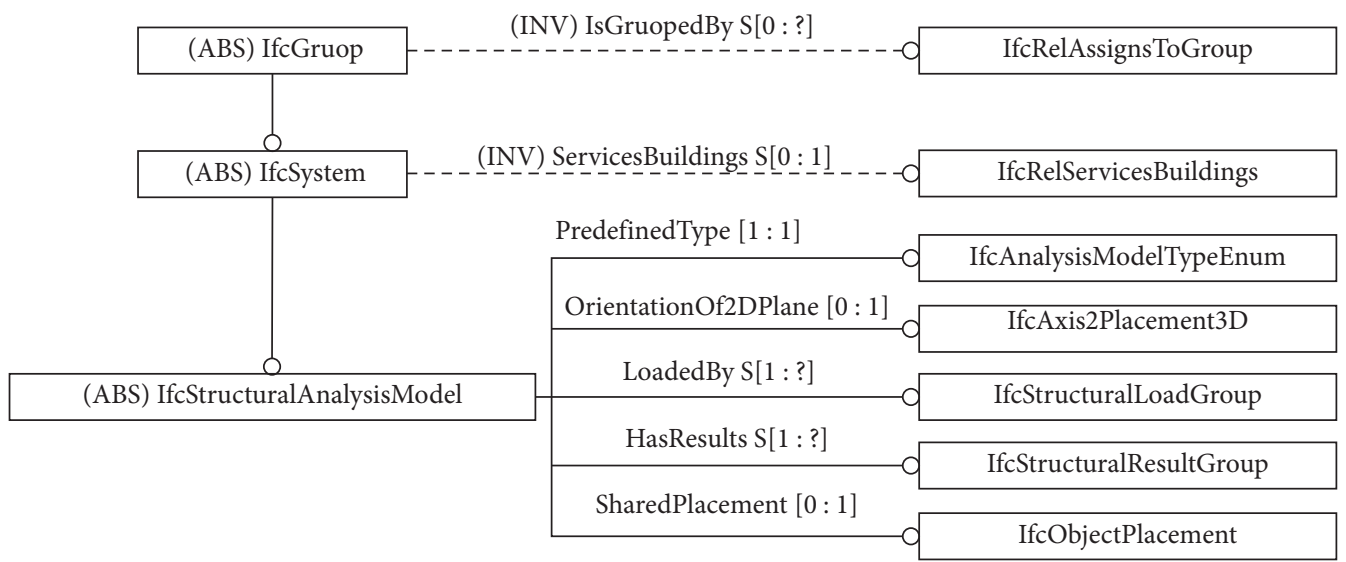

FIgURE 24: Properties of IfcStructuralAnalysisModel.

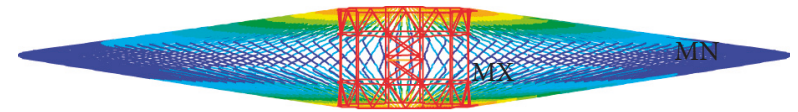

(a)

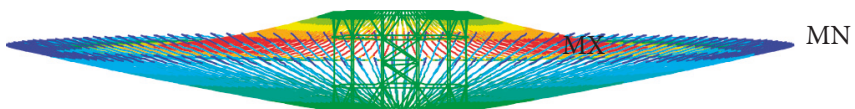

(b)

Figure 25: The final displacement of steel cable structure (a) under natural fire and (b) under standard ISO fire.

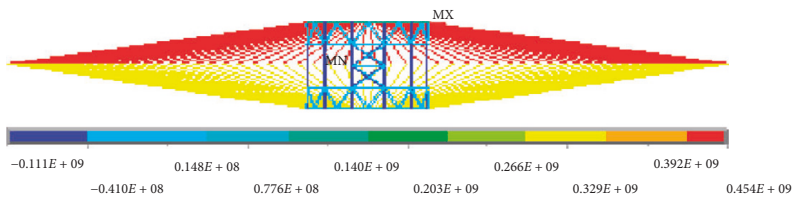

(a)

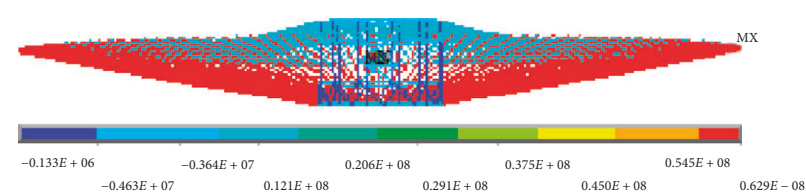

(b)

Figure 26: The stress of a steel cable structure (a) under natural fire and (b) under standard ISO fire. 
different thermal loads at peak time. Figure 27 shows a comparison between two of the time-dependent predicted tension forces of a single steel cable with respect to the different temperature environments.

From the analysis results, we can observe the change of stress state in the steel structure under fire service loads. The prestress in the steel cables has been lost due to the increase of temperature. Meanwhile, the decrease of elastic modulus and yield strength has become more significant due to the increase of the steel temperature and the decrease of prestress in the cables. The loss of prestress in the upper cables is up to about $15 \%$ at the time of peak temperature but only about $2.7 \%$ in the lower cables. Stress redistribution occurred in the steel roof structural system due to the asymmetrical distribution of the temperature field. The maximum stress occurred in the central steel truss.

Finally, we also collect all the information about the structure analysis and feedback all the information to Revit building information model based on Revit API. Therefore, it presents a preliminary framework for the application of BIM model in structure analysis according to the information requirements at the fire safety designs.

6.2.2. Fire Safety Evacuation Simulations. The BIM model containing fire simulation analysis results can also support to simulate the emergency evacuation of this gymnasium. In this paper, a detailed analysis of emergency evacuation is completed with the egress and human movement simulator Pathfinder developed by Thunderhead Engineering. The FDS file outputted by parse tool in the last chapter can also be imported into Pathfinder. After importing the $3 \mathrm{D}$ data from FDS files, which provides the most helpful information for accurately extracting navigation area, we need to use the extract floors tool to extract navigation area on a room by room basis.

Evacuation paths can be confirmed as long as targets and directions are specified. In the model, the flow is regarded to circulate directionally within or among various types of architectural elements through "doors" [32]. The sequence during evacuation is established based on characteristics of the structure, as shown in Figure 28. Utilizing the geometry features of each element, this strategy fully reflects human experience and expands knowledge library of occupants. Thus, the behavior according to these rules will conform to practical situation.

It needs to be clarified that the above rules may not be applicable in some particular circumstances, such as congestion appears or smoke spreads within target enclosure. Then, adjustments must be made to the strategy. Occupants change current target for secondary one or select subordinate move direction for the balance of safety and efficiency.

Before running the evacuation simulation model, we also need to design evacuation scenario referring to the evacuation data at home and abroad in accordance with the principle of the unfavorable conservative. Then, we run the Pathfinder model and get the results including summary report file containing information about the simulation geometry, simulation performance, and usage information for each room, stairway, and door. And, Pathfinder 2015 provides the ability to view animation results from the Fire Dynamics Simulator (FDS) from NIST. Through a comparative analysis on fire simulation and personnel evacuation result, we can optimize the building model in order to achieve the safety requirements. Based on the fire scenario described above, an evacuation simulation was performed. The results of the temperature field and smoke distribution calculated by FDS were imported into the evacuation model.

Occupants were generated as randomly located before evacuation starts. Initial location and inherent qualities such as gender were randomly given to each individual. Some evacuation properties relevant to qualities were then assigned accordingly. Health and mobility statuses were assumed to be normal for occupants. The size of the space grid each occupant takes up was taken as $0.4 \mathrm{~m} \times 0.4 \mathrm{~m}$. Evacuation begins when a fire alarm detects smoke, i.e., when the gas volume fraction somewhere in the field exceeds $2 \%$. Reaction time was assumed as $10 \mathrm{~s}$ for the occupants near the fire source, $20 \mathrm{~s}$ for others.

Figure 29 shows the profile of the evacuation process. The figure represents the evacuation state at a certain time after the fire occurred.

Some experimental data have indicated the relationship between the duration occupants is exposed to a certain volume of toxic substances and the corresponding hazard to the human body. Referring to this, it is possible to estimate the potential hazard due to toxic gases and the heat release to occupants in the fire field.

The critical fire danger condition could be determined by the following criteria:

(i) The critical temperature of the fumes layer could be set as $180^{\circ} \mathrm{C}$.

(ii) The value of critical soot layer temperature in the model is determined to be $115^{\circ} \mathrm{C}$.

(iii) When concentration of CO reaches $2500 \mathrm{ppm}$, serious hazard to health exists. The critical height of a man's eyes is normally $1.2 \sim 1.8 \mathrm{~m}$, the model takes it as $1.6 \mathrm{~m}$.

It can be seen from the simulation process that the speed changed as a result of obstacle avoidance in the evacuation routine and the influence of the evacuees. In the process of evacuation, due to the limited number of exits and aisles, congestion occurred. Thus, the number and width of the exits and aisles produce an important effect on safe evacuation. The evacuation time can be read from the output file. The total time of evacuation was $479 \mathrm{~s}$. Compared with the potentially structural insecurity critical time and the direct hazards, occupants may suffer in fire, the evacuation will be safe, and the remainder of available safety time will be enough.

Finally, we also collect all the analysis result about the evacuation simulation and feedback all the information of evacuation simulation results to the BIM model. 


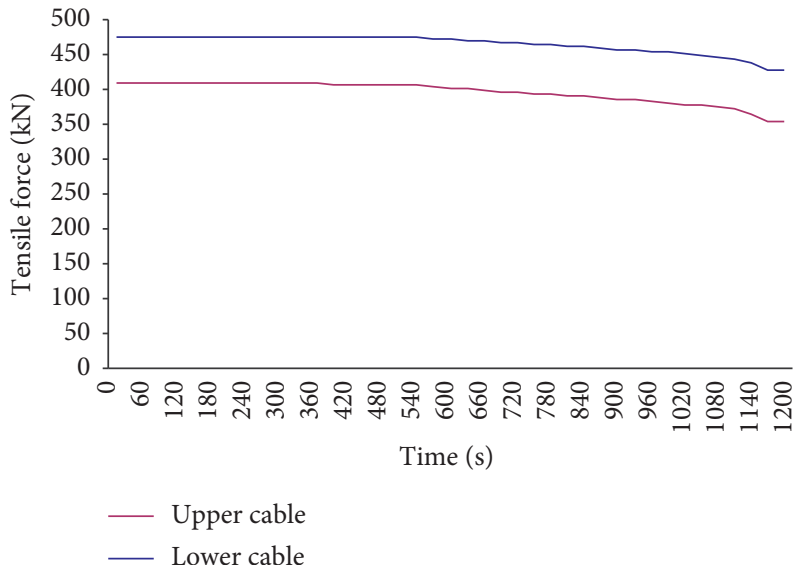

(a)

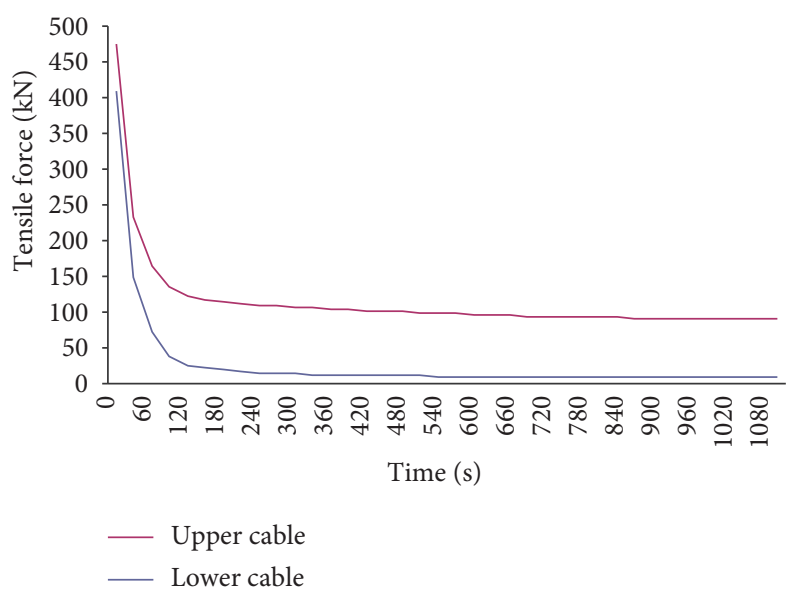

(b)

FIgURE 27: The tension force of central steel truss structure (a) under natural fire and (b) under standard ISO fire.

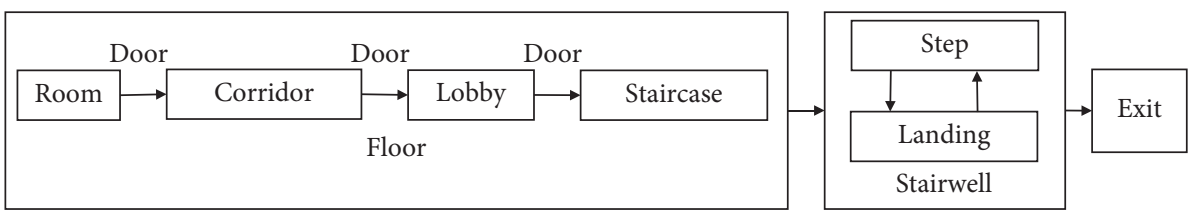

FIGURE 28: Evacuation sequence based on characteristics of structure.

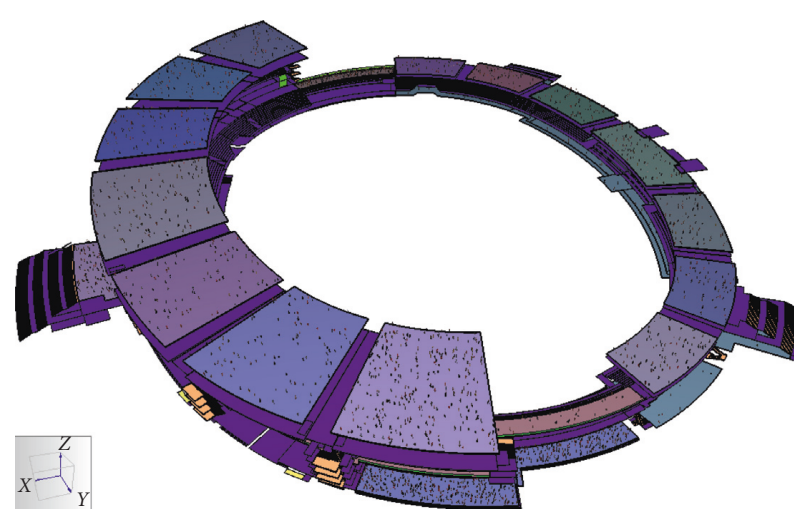

FIgURE 29: The scenario of evacuation.

\section{Conclusions}

The work in this study has successfully implemented a quick and accurate approach of IFC- and FDS-based information sharing for building fire safety analysis.

Through a series of theoretical study and practical exploration, the main achievements of the subject consist of the following: (1) according to comparison of modeling method in IFC physical files and FDS input files, the data parsing tool for direct information sharing and exchange between them are successfully developed. The coordinate systems of two common default geometry representation methods in IFC files, sweeping representation and boundary representation, which support both basic and complex building geometries can be transformed into FDS files quickly and accurately. (2) Semantic information sharing is also supported by this approach through outer database and the IFC file extension. The method of expanding IFC entities relevant to FDS simulation information is described, which can complete the storage of the fire simulation information in the IFC data model. The visualization of these data in BIM applications is based on the API of Autodesk Revit, which can read the fire simulation results from IFC data files and displayed in Revit platform. (3) The BIM model restoring fire simulation results can support other performance-based designs of the building, such as structural fire-resistant design and evacuation design. And, all of the analysis results including building fire simulation, structure safety design, and evacuation simulation can be feedback to BIM applications, of which the visualization was based on Autodesk Revit to establish a framework of IFC- and FDS-based information sharing for building fire safety analysis.

This study has several limitations that need further investigation. Firstly, given the complexity of data structure, especially IFC data standard, extension of IFC entity for fire simulation result storage in this paper only allows for the extension of generic level entities, mainly referring to some property sets, and geometric information sharing only supports for sweeping representation and boundary representation geometry, which are two of common default representations in IFC data standard. Secondly, the setup of the computational mesh has a significant impact on the accurateness of transformation of coordinate systems and geometry description between IFC physical files and FDS input files. The future direction and challenge are to support the automatic calculation and optimization of computational mesh for better 
physical dimensions and resolution. In addition, in this paper, only IFC physical files and FDS input files are discussed as the information sharing foundation between mainstream BIM applications and fire simulation software. With a growing interest in the building fire safety analysis, other fire simulation software with different data schema and other IFC versions will be used in the IFC-based information integration. Therefore, both geometric and semantic information sharing between BIM applications and fire simulation software in this paper have specific limitations in data schema and data version. However, understanding all the limitations of this paper not only makes a significant opportunity for further research on information sharing between BIM applications and fire simulation software but also supports the further research relevant to IFC-based information integration for the development of the use of BIM models for the performance-based design of building as well.

\section{Data Availability}

The .fds data used to support the findings of this study are included within the supplementary information file.

\section{Conflicts of Interest}

The authors declare that they have no conflicts of interest.

\section{References}

[1] C. M. Eastman, BIM Handbook: A Guide to Building Information Modeling for Owners, Managers, Designers, Engineers and Contractors, Wiley, Hoboken, NJ, USA, 3rd edition, 2018.

[2] R. A. Kivits and C. Furneaux, "BIM: enabling sustainability and asset management through knowledge management," The Scientific World Journal, vol. 2013, Article ID 983721, 14 pages, 2013.

[3] M. Spearpoint and J. Dimyadi, "Sharing fire engineering simulation data using the IFC building information model," in Proceedings of the 2007 International Congress on Modelling and Simulation, Christchurch, New Zealand, December 2007.

[4] M. Laakso and A. Kiviniemi, "The IFC standard-a review of history, development, and standardization," Electronic Journal of Information Technology in Construction, vol. 17, pp. 134-161, 2012.

[5] K. McGrattan, S. Hostikka, R. McDermott, J. Floyd, C. Weinschenk, and K. J. N. s. p. Overholt, Fire Dynamics Simulator Technical Reference Guide Volume 1: Mathematical Model, Vol. 1019, National Institute of Standards and Technology, Gaithersburg, MD, USA, 2013.

[6] H. Nelson, "From phlogiston to computational fluid dynamics," Fire Protection Engineering, vol. 13, pp. 9-17, 2002.

[7] G. E. Gorbett, "Computer fire models for fire investigation and reconstruction," in Proceedings of the 2008 International Symposium on Fire Investigation and Technology, Cincinnati, OH, USA, May 2008.

[8] X. Yi, C. Lei, J. Deng et al., "Numerical simulation of fire smoke spread in a super high-rise building for different fire scenarios," Advances in Civil Engineering, vol. 2019, Article ID 1659325, 11 pages, 2019.

[9] J.-Y. Jung, S.-G. Kang, H.-J. Yoon, K.-B. Shin, and J.-K. Lee, "Analysis of heat and smoke flow according to platform screen door and fan conditions on fire in underground platform," Advances in Civil Engineering, vol. 2018, Article ID 4803058, 8 pages, 2018.

[10] Y. Xu, E. Kim, K. Lee, J. Ki, and B. Lee, "FDS simulation high rise building model for unity 3D game engine," International Journal of Smart Home, vol. 7, no. 5, pp. 263-274, 2013.

[11] J. Glasa, L. Valasek, P. Weisenpacher, and L. Halada, "Use of PyroSim for simulation of cinema fire," International Journal on Recent Trends in Engineering \& Technology, vol. 7, no. 2, pp. 51-56, 2012.

[12] L. Valasek, "The use of PyroSim for creation of the input FDS geometry for cinema fire simulation," in Proceedings of the 2012 European Conference of Systems, Paris, France, December 2012.

[13] R. Volk, J. Stengel, and F. Schultmann, "Building information modeling (BIM) for existing buildings-literature review and future needs," Automation in Construction, vol. 38, pp. 109127, 2014.

[14] J. Zhang and R. R. Issa, "Collecting fire evacuation performance data using BIM-based immersive serious games for performance-based fire safety design," in Proceedings of the 2015 International Workshop on Computing in Civil Engineering, pp. 612-619, Austin, TX, USA, June 2015.

[15] M.-Y. Cheng, K.-C. Chiu, Y.-M. Hsieh, I.-T. Yang, J.-S. Chou, and Y.-W. Wu, "BIM integrated smart monitoring technique for building fire prevention and disaster relief," Automation in Construction, vol. 84, pp. 14-30, 2017.

[16] F. Mirahadi, B. McCabe, and A. Shahi, "IFC-centric performance-based evaluation of building evacuations using fire dynamics simulation and agent-based modeling," Automation in Construction, vol. 101, pp. 1-16, 2019.

[17] N. Li, B. Becerik-Gerber, B. Krishnamachari, and L. Soibelman, "A BIM centered indoor localization algorithm to support building fire emergency response operations," Automation in Construction, vol. 42, pp. 78-89, 2014.

[18] J. Dimyadi, W. Solihin, and R. Amor, "Using IFC to support enclosure fire dynamics simulation," in Advanced Computing Strategies for Engineering, vol. 10864, pp. 339-360, 2018.

[19] M. Spearpoint, "Transfer of architectural data from the IFC building product model to a fire simulation software tool," Journal of Fire Protection Engineering, vol. 17, no. 4, pp. 271-292, 2007.

[20] M. Spearpoint, "Extracting fire engineering simulation data from the IFC building information model," in Handbook of Research on Building Information Modeling and Construction Informatics: Concepts and Technologies, pp. 212-238, IGI Global, Hershey, PA, USA, 2010.

[21] Y.-x. Chen, J.-y. Shi, and M. Chen, "Research on IFC-based BIM modelling for fire analysis," Fire Science and Technology, vol. 36, no. 10, pp. 1371-1373, 2017.

[22] T. Liebich, Y. Adachi, J. Forester, J. Hyvarinen, K. Karstila, and J. Wix, "International alliance for interoperability industry foundation classes IFC2x edition 3," 2006, https:// standards.buildingsmart.org/IFC/RELEASE/IFC2x3/FINAL/ HTML/.

[23] J. A. W. Dimyadi, M. Spearpoint, and R. Amor, "Generating fire dynamics simulator geometrical input using an IFC-based building information model," Electronic Journal of Information Technology in Construction, vol. 12, pp. 443-457, 2007.

[24] J. Dimyadi, M. Spearpoint, and R. Amor, "Sharing building information using the IFC data model for FDS fire simulation," Fire Safety Science, vol. 9, pp. 1329-1340, 2008. 
[25] V. Bazjanac and D. B. Crawley, The Implementation of Industry Foundation Classes in Simulation Tools for the Building Industry, University of California, Berkeley, CA, USA, 1997.

[26] C. Clemen and L. Gründig, "The industry foundation classes (IFC)-ready for indoor cadastre?," in Proceedings of 23rd International FIG Congress, Munich, Germany, October 2006.

[27] J.-c. Dao and J. y. Shi, "Building fire safety analysis based on BIM," Fire Science and Technology, vol. 36, no. 3, pp. 391-394, 2017.

[28] U. Rüppel and K. Schatz, "Designing a BIM-based serious game for fire safety evacuation simulations," Advanced Engineering Informatics, vol. 25, no. 4, pp. 600-611, 2011.

[29] B. Liu, Z. Liu, D. Sun, and C. Bi, "An evacuation route model of crowd based on emotion and geodesic," Mathematical Problems in Engineering, vol. 2018, Article ID 5397071, 10 pages, 2018.

[30] J. Shi, W. Shi, and A. Ren, "An integrated model for the fire safety analysis of large space buildings," Advances in Structural Engineering, vol. 14, no. 5, pp. 763-775, 2011.

[31] A. Ren, J. Shi, and W. Shi, "Integration of fire simulation and structural analysis for safety evaluation of gymnasiums-with a case study of gymnasium for Olympic Games in 2008," Automation in Construction, vol. 16, no. 3, pp. 277-289, 2007.

[32] A. Ren, C. Chen, J. Shi, and L. Zou, "Application of virtual reality technology to evacuation simulation in fire disaster," in Proceedings of the 2006 International Conference on Computer Graphics \& Virtual Reality, Las Vegas, NV, USA, June 2006. 


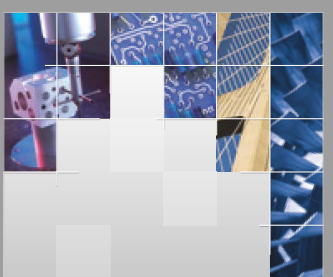

\section{Enfincering}
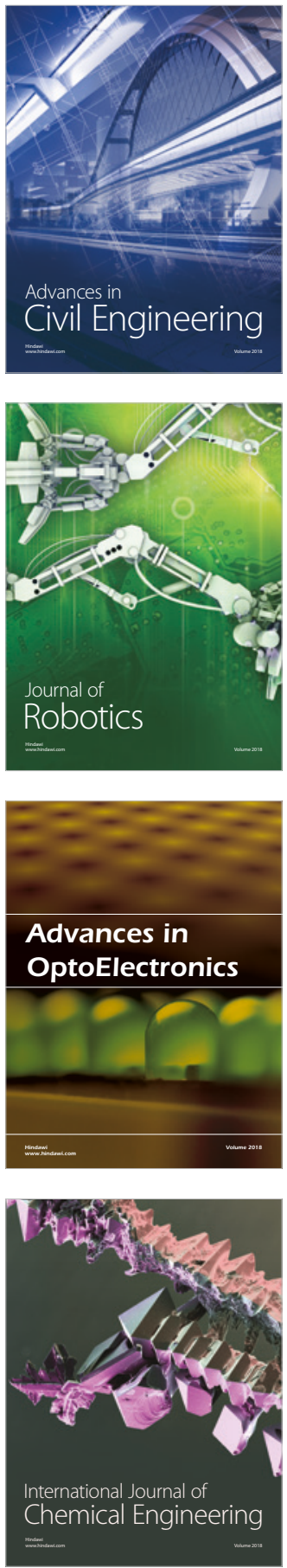

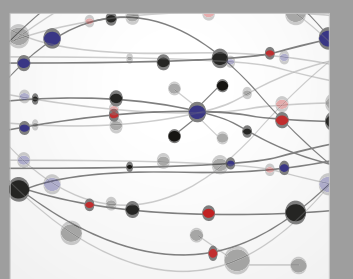

\section{Rotating \\ Machinery}

The Scientific World Journal

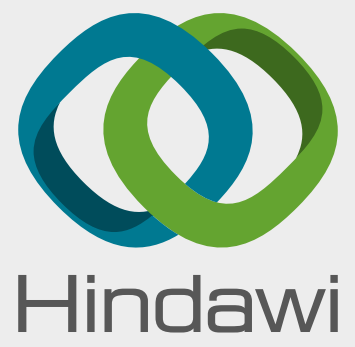

Submit your manuscripts at

www.hindawi.com
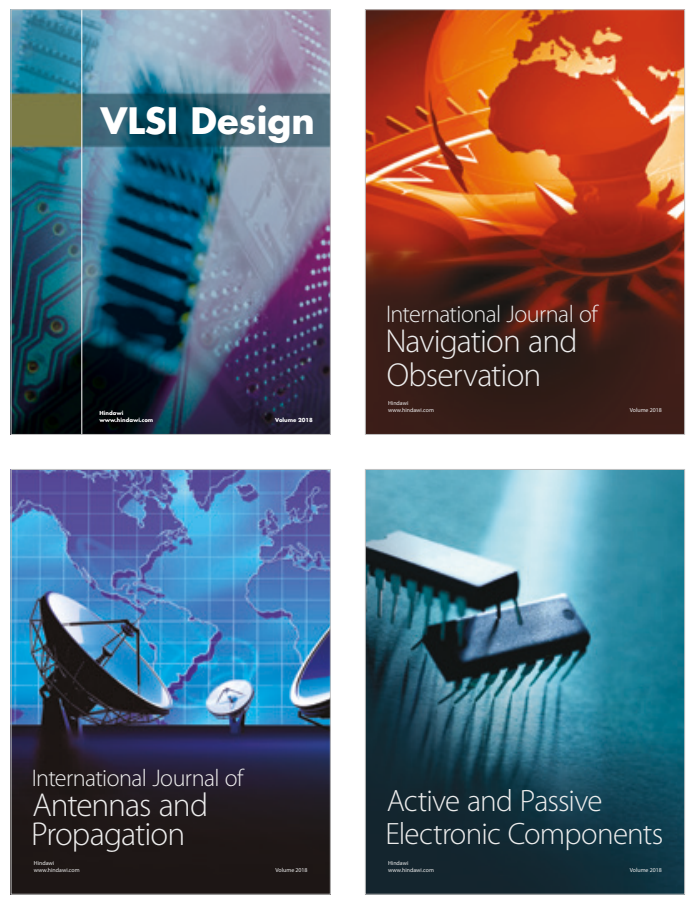
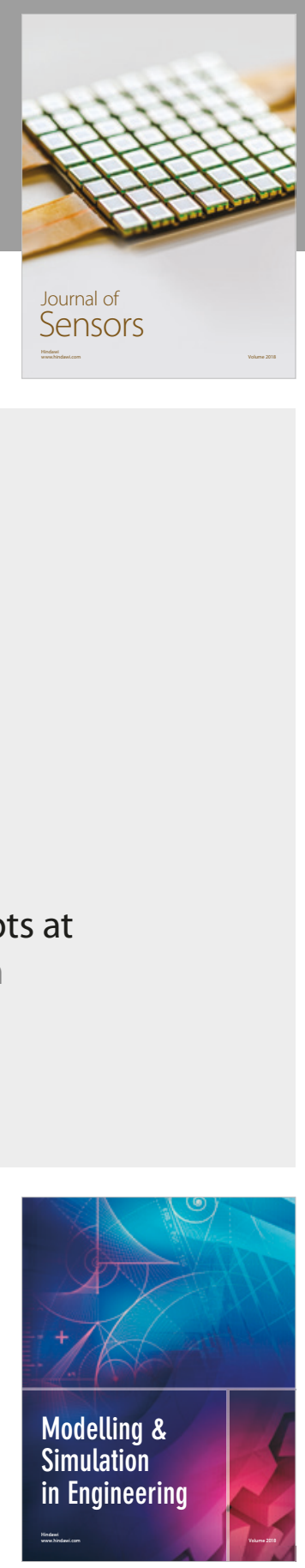

\section{Advances \\ Multimedia}
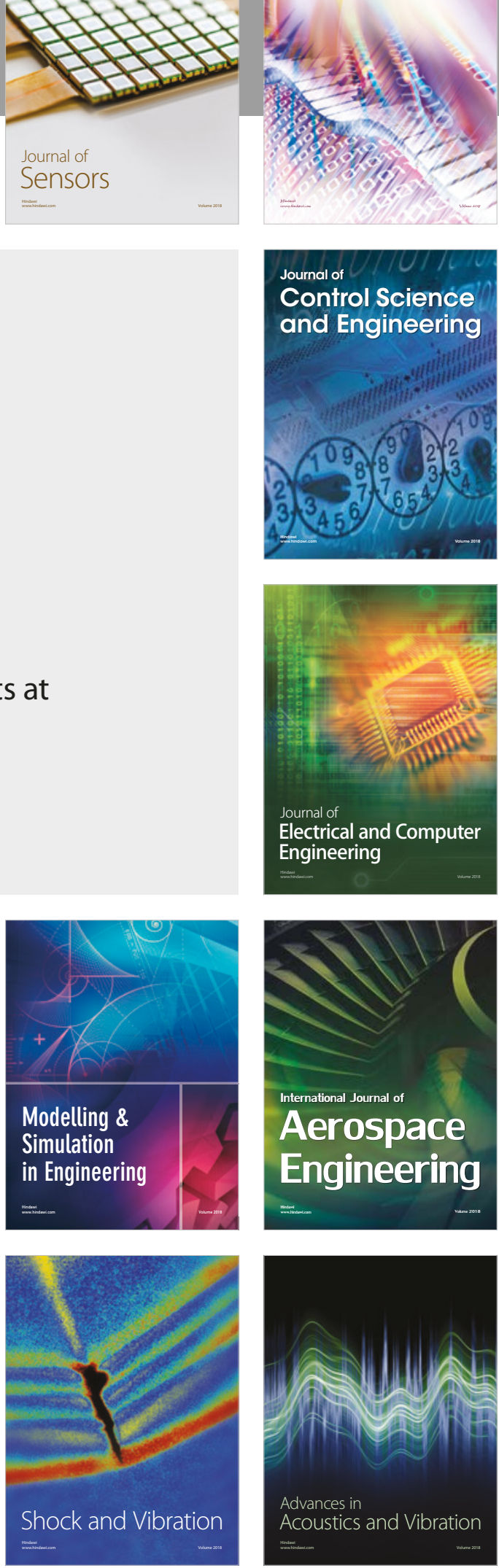